\title{
Un derecho europeo... ¿para qué contrato? Análisis sobre las fronteras del contrato en derecho comparado*
}

\author{
Martin Oudin \\ Maître de Conférences \\ Universidad François Rabelais (Tours, Francia)
}

Recibido: 13.11 .07

Aceptado: 04.12 .07

Resumen: El objeto de estudio de este artículo es la unificación del derecho de los contratos en Europa. Varios textos han sido ya elaborados y podrían prefigurar lo que, el día de mañana, podría constituir el Código Europeo de los Contratos. Cualquiera que sea la naturaleza de sus normas, no tendrán eficacia más que en el caso de que su ámbito de aplicación sea claramente identificado, es decir, si los sistemas jurídicos europeos no se ponen de acuerdo previamente en lo que puede considerarse un contrato. En este momento las diferencias son numerosas e importantes. El análisis de algunas de ellas nos conduce a cuestionar la aproximación clásica al contrato, que consiste en definirlo como acuerdo de voluntades destinado a crear obligaciones entre las partes. Ni el acuerdo de voluntades ni la creación de obligaciones nos permite determinar qué es un contrato y qué no lo es. Por el contrario, una definición basada en la función socio-económica del contrato -si no la producción, al menos la previsión- podría federar las concepciones europeas del contrato.

Palabras clave: Derecho de los contratos, naturaleza jurídica, unificación del Derecho privado.

Abstract: Studies are currently being carried out on the unification of contract law in Europe. Several texts have already been drafted and announce a possible future European contract code. Whatever the quality of these rules may be they will only be effective if their field of application is precisely defined, i.e. if European lawyers first agree on what a contract is. At the present time, national laws profoundly diverge on this point. An analysis of some of the main differences raises a number of questions concerning the classical view that a contract is an agreement giving rise to obligations between the contracting parties. Neither the principle of a reciprocal agreement nor the creation of obligations permit a clear distinction to be made between those situations that are contractual and those that

* Traducido por María Pilar Canedo, Marta Casado y Luis Gordillo. El texto de este artículo fue publicado inicialmente como «Un droit européen ... pour quel contrat? Recherches sur les frontières du contrat en droit comparé», en la Revue internationale de droit comparé, n. ${ }^{\circ}$ 3, 2007. La traducción de este trabajo se enmarca dentro del proyecto de investigación «La comunitarización del Derecho privado», con referencia IT-401-07 subvencionado por el Departamento de Educación, Universidades e Investigación del Gobierno Vasco (2007-2009), cuyo investigador principal es el profesor Ricardo de Ángel Yagüez. 
are not. On the other hand, a definition based on the socio-economic function of contracts - production or, at least, anticipation-could bring together national conceptions of what constitutes a contract.

Key words: Contract Law, Legal Nature, Unification of Private Law.

Sumario: I. El contrato como acuerdo de voluntades. A. Antes del acuerdo: la responsabilidad precontractual. B. Fuera del acuerdo: los terceros. 1. Las estipulaciones por terceros. 2. Acciones directas. C. El acuerdo incierto. 1. Incertidumbre sobre la existencia misma del acuerdo. 2. Incertidumbre sobre el valor contractual del acuerdo. D. El acuerdo incompleto.- - II. El contrato como fuente de obligaciones. A. Contenido no obligacional del contrato. B. Obligaciones no contractuales en cuanto a su objeto. C. Obligaciones sin contrapartida.-Conclusión.

1. El contrato establece una relación jurídica entre dos individuos; en ese sentido, resulta una excepción a la individualidad que es la regla entre dos individuos. Excepcionalmente lleva consigo un conjunto de reglas derogatorias del derecho común de obligaciones tanto desde el punto de vista procesal (competencia territorial, prescripción) como sustantivo (condiciones y efectos de una posible responsabilidad, incidencia de las previsiones de las partes...). El mismo derecho transitorio se ve afectado por la naturaleza contractual de un litigio: escapando al efecto inmediato de las legislaciones nuevas, los contratos son en principio regidos por la regla vigente en el momento de su firma. Lo mismo ocurre en Derecho Internacional Privado, que establece que el contrato estará como regla general regida por la ley elegida por las partes.

Constituye por lo tanto una regla clásica y casi banal la constatación de hasta qué punto la calificación de una relación jurídica como contractual es determinante para fijar las normas que le son aplicables. En la actualidad existen sin embargo otros motivos que nos llevan a analizar esta cuestión. Resulta previsible ya en este momento una unificación, si no del derecho civil europeo en su totalidad, del derecho europeo de los contratos. Varias han sido las iniciativas que han visto la luz en este ámbito en los últimos tiempos; entre ellos destacan el proyecto Gandolfi de la Academia de privatistas europeos ${ }^{1}$ y el Von Bar del Grupo de estudio sobre el código Civil Europeo $^{2}$. A diferencia de los instrumentos no vinculantes como los princi-

${ }^{1}$ Los trabajos de esta Academia pueden ser consultados en la página <http://www.accademiagiusprivatistieuropei.it/>. Un anteproyecto, acompañado de un voluminoso informe comparado del coordinador, ha sido publicado (en francés) por el editor italiano Giuffrè en 2004, bajo el título Code européen des contrats-Livre premier.

${ }^{2}$ V. el sitio <http://www.sgecc.net/>. 
pios Unidroit relativos a los contratos del Comercio Internacional o a los Principios del Derecho europeo de los contratos, los proyectos a que nos referimos aspiran a tener fuerza obligatoria. Resulta por tanto necesario preguntarse nuevamente a qué realidades pretenden ser aplicadas las nuevas propuestas. Al contrato, sí, pero ¿qué es un contrato? Sería conveniente, en el momento de llevar a cabo tal unificación, asegurarse de que definimos exactamente su contenido. El contrato no tiene quizá la misma significación ni la unificación del contrato el mismo alcance según nos situemos a uno u otro lado del canal de la Mancha, de los Alpes o del Rin.

2. Resulta necesario dar una definición supranacional del contrato como paso previo a la aplicación de las reglas que están en vías de aplicación. Pero ésta es una tarea ardua. Un rápido análisis del derecho comparado resulta suficiente para convencerse de que existen profundas diferencias que separan los sistemas jurídicos europeos -por no citar más que ellos ${ }^{3}-$. Para no comprometer la puesta en marcha de los instrumentos internacionales en la materia, ha resultado a veces necesario prohibir cualquier calificación «nacionalista». Según una jurisprudencia constante del Tribunal de Justicia de las Comunidades Europeas, la noción de materia contractual a fin de aplicar la Convención de Bruselas de 27 de septiembre de 1968, sobre competencia judicial internacional, reconocimiento y ejecución de resoluciones judiciales en materia civil y mercantil (convertido en Reglamento «Bruselas I» de 22 de diciembre de 2000) es una noción autónoma que debe ser interpretada refiriéndose principalmente a los objetivos y al sistema de la Convención ${ }^{4}$. Resulta por tanto que a las diversas concepciones nacionales de «contrato» debe añadirse la concepción internacional que puede no coincidir según se plantee la aplicación de normas de conflictos de jurisdicciones o normas de conflictos de leyes ${ }^{5}$.

Si analizamos la Convención de Roma de 19 de junio de 1980 sobre Ley aplicable a las obligaciones contractuales, comprobamos desde su primer precepto que los redactores se enfrentan a dificultades de definición de la materia contractual. Tras declarar que la Convención se aplica a «las obligaciones contractuales», el artículo 1 procede a la enumeración de cuestiones excluidas del ámbito de aplicación de la Convención. Si algunas de esas exclusiones encuentran su justificación en la preocupación de no producir colisión con otros instrumentos internacionales preexistentes (tal como suce-

${ }^{3}$ V. especialmente G. ALPA, «Le contrat individuel et sa définition», RIDC, 1988, p. 327.

${ }^{4}$ TJCE, 8 de marzo de 1988, Arcado, RCDIP 1988, p. 610, comentada por GAUDEMENTTallon; A. Huet, Jdi 1989, p. 453; B. Audit, D. 1989, somm. p. 344

${ }^{5}$ En este sentido, v. V. Heuze, «La notion de contrat en droit international privé», Trav. Com. Fr. DIP 1997-1998, p. 319. 
de, por ejemplo, en los casos del cheque o de la letra de cambio), otros buscan fundamentalmente prevenir eventuales divergencias de interpretación por parte de los jueces nacionales. Por ejemplo, podemos dudar de la posibilidad de considerar contratos los regímenes matrimoniales, la representación o incluso el trust: de hecho, la calificación no es la misma de un sistema a otro. La convención previene toda dificultad declarándose inaplicable a esas instituciones. Pero ella no se limita a una definición extrínseca del contrato, por oposición a las categorías que le son ajenas. El convenio busca igualmente determinar su aplicabilidad a diferentes aspectos del contrato: la interpretación, la ejecución, las consecuencias de la inejecución, las consecuencias de la nulidad, etc ${ }^{6}$. No es éste el menor de los problemas de calificación que plantea el contrato. No es por tanto suficiente considerar que una situación es globalmente contractual. Resulta necesario pronunciarse sobre la naturaleza de cada uno de los aspectos de la situación que pueda ser objeto de duda: ¿tiene la fase previa o posterior de un contrato naturaleza contractual? ¿En qué medida los terceros son integrados en la esfera contractual? ¿Cuál es la naturaleza de las obligaciones no expresamente estipuladas por las partes? Etcétera. Debe reconocerse que sobre todas estas cuestiones la Convención de Roma resulta muy incompleta.

3. Resulta fácil ser consciente de la amplitud de la tarea que supone delimitar las fronteras del contrato en Derecho comparado. Ni siquiera es evidente que tal estudio sea posible dado el número de cuestiones que resultaría necesario abordar y la diversidad de los sistemas jurídicos nacionales, incluso si limitamos el estudio a los sistemas de Estados miembros de la Unión Europea. Nos proponemos por tanto simplemente poner de manifiesto un limitado número de divergencias (quizá las más importantes), para extraer de ellas enseñanzas sobre el método que debería presidir cualquier tentativa de definición del contrato.

Cabe plantearse dos acercamientos diferentes a la cuestión ${ }^{7}$. El primero de ellos -que podríamos definir como normativa- es la propia, fundamentalmente, del Derecho francés. Consiste en considerar contrato todo acuerdo de voluntades no sólo si responde a la definición dada por el artículo 1101 del Código Civil ${ }^{8}$, sino también si obedece a las condiciones de validez enumeradas (de manera incompleta) por el artículo 1108 del mismo Código 9 . En

\footnotetext{
${ }^{6}$ Art. 10 «Ámbito de la ley del contrato».

${ }^{7}$ Resultan interesantes las dudas de la Academia de Privatistas europeos acerca de las dos aproximaciones en el Code européen des contrats-Livre premier, op. cit. p. 93,

${ }^{8} \ll$ El contrato es una convención por medio de la cual una o varias personas se obligan frente uno o varios otros sujetos, a dar, hacer o no hacer una cosa».

${ }^{9}$ «Cuatro condiciones son esenciales para la validez de un acuerdo: el consentimiento de la parte que se obliga; su capacidad contractual; un objeto cierto que constituye la materia del acuerdo; una causa lícita en la obligación».
} 
un sistema como éste, el juez reconoce eficacia jurídica al acuerdo cuando ha sido concluido respetando las reglas preestablecidas. Es el sentido del artículo 1134 del Código Civil que reconoce fuerza de ley tal sólo a los convenios «legalmente formados». De este modo, las cuestiones de existencia y de validez del contrato se confunden. Siguiendo la otra aproximación, funcional, el juez no debe reconocer más que los acuerdos de voluntad que cumplan una determinada función económica o social. Sólo en esa condición puede el contrato acceder al rango jurídico de contrato. Es fundamentalmente la concepción del Derecho inglés ${ }^{10}$. Para ella, en efecto, el contrato supone un intercambio económico (bargain), en el cual, en general, las partes consienten en experimentar un perjuicio (detriment) en consideración del beneficio (benefit) que obtienen. Esta concepción resulta fundamentalmente del hecho de que, en la medida en que el derecho ingles juzga necesario inventar el derecho del contrato ${ }^{11}$, el modelo ha sido el contrato comercial o de consumo ${ }^{12}$. Ello se traduce fundamentalmente en la exigencia de la consideration: el acuerdo invocado no es un contrato más que en el caso de que cualquiera de las partes se comprometa a ofrecer una cosa o una prestación en contrapartida de lo que reciba ${ }^{13}$.

Estas dos aproximaciones teóricas al contrato tienen una influencia no desdeñable en la delimitación de la materia contractual, tal como tendremos ocasión de constatar. Sin embargo, no debemos exagerar su relevancia. En primer lugar porque tienen en común un presupuesto: el contrato no existe sin acuerdo de voluntades. Esta afirmación alimenta buena parte de las dificultades que supone la definición de los contratos, fundamentalmente desde el punto de vista del derecho comparado. Todos los sistemas jurídicos europeos reconocen en mayor o menor medida la misma función jurídica al contrato: es el medio ordinario por el que los individuos aceptan vincularse jurídicamente unos a otros creando entre ellos relaciones de obligación. Pero a su vez, esta función creadora de obligaciones concentra buena parte de los problemas de delimitación de la materia contractual.

Organizaremos por tanto este estudio alrededor de una doble afirmación provisionalmente aceptada: el contrato no existe sin acuerdo de voluntades; tan sólo interesa al derecho en la medida en que resulta generador de obligaciones.

${ }^{10}$ Conviene aclarar que ésta es una aproximación propia del derecho inglés, donde la definición es discutida. V. G. ALPA, op. cit., especialmente pp. 330 y siguientes.

${ }^{11}$ En los casos en que no se conocía más que un derecho de contratos, v. sobre esta evolución P. S. АтІҮAн, The Rise and Fall of Freedom of Contract, 1979, pp. 681-693.

${ }^{12}$ V. S. Hedley, «Keeping Contract in its Place_Balfour v. Balfour and the Enforceability of Informal Agreements», Oxford Journal of Legal Studies, 1985, p. 391.

${ }^{13}$ Todas las obras dedicadas al derecho de los contratos consagran amplios desarrollos a esta cuestión, evocada en este punto de manera simple. V. p. ej. G. H. TREITEL, The Law of contract, 11 eme éd. 2003, p. 67, s. V. también B.S. MARKESINIS, «La notion de consideration dans la Common Law: vieux problèmes; nouvelles théories», RIDC 1983, p. 735. 


\section{EL CONTRATO COMO ACUERDO DE VOLUNTADES}

4. Por muy dirigido que pueda estar, el contrato se percibe en todo caso como el acuerdo de voluntades. Éste es un denominador común a todas las concepciones jurídicas de contrato. No resulta sorprendente por tanto que resulte problemática la calificación cuando la voluntad de las partes es incierta, sea en su existencia o alcance. A fortiori, el contrato debería ser excluido cuando no existe acuerdo de voluntades, sea porque las negociaciones no han llegado a buen término, sea porque nunca han tenido lugar.

\section{A. Antes del acuerdo: la responsabilidad precontractual}

5. Fuera del supuesto en que las partes hayan tenido la precaución de dar una cobertura contractual a la fase de negociación del contrato, la calificación de los incumplimientos que se suscitan en la fase de las discusiones previas plantea dificultades ${ }^{14}$. Las decisiones que se abordan en cada sistema son tributarias, en este ámbito de modo especial, de los principios generales de la responsabilidad vigentes en cada Estado.

Algunos sistemas jurídicos pueden sancionar el incumplimiento precontractual porque se han dotado de un principio general de la responsabilidad aplicable cualquiera que sea el hecho dañoso. Este principio se establece en Francia y Bélgica en el artículo 1382 del Código Civil ${ }^{15}$, en Italia por el artículo 2043 del Código Civil ${ }^{16}$. Si en principio todo hecho dañoso es generador de responsabilidad no hay lugar para excluir a los que hayan sido generados durante la negociación de un contrato. El recurso a la responsabilidad es por tanto posible aunque no haya ninguna disposición legal que prevea expresamente la responsabilidad precontractual. Sin embargo, tal disposición existe en alguna legislación: así, el 1337 del Código Civil italiano dispone que las partes, durante las negociaciones en la formación, deben actuar conforme a la buena fe. El anteproyecto Catalá de reforma del derecho de obligaciones contiene una disposición muy próxima, el art. 1104: «La iniciativa, el desarrollo y la ruptura de las negociaciones son libres, pero deben satisfacer las exigencias de la buena fe. El fracaso de una negociación

${ }^{14}$ V. M. FonTAINE (dir.), Le processus de formation du contrat- Contributions comparatives et interdisciplinaires à l'harmonisation du droit européen, Bruxelles, Bruylant, 2002, que realiza, especialmente en la contribución de B. DE CONINCK, aportaciones muy relevantes a esta cuestión.

15 «Todo hecho humano que causa un daño a otro obliga a aquél por cuya causa se ha producido a repararlo».

16 «Todo hecho, doloso o culposo, que causa a otro un daño injusto, obliga a su autor a repararlo». 
no puede ser fuente de responsabilidad más que si puede imputarse a la mala fe de una de las partes».

Otros sistemas jurídicos no conocen el principio de responsabilidad extracontractual. Es el caso del derecho inglés, que sanciona un grupo relativamente heterogéneo de ilícitos civiles (torts) particulares ${ }^{17}$ fuera de los cuales ninguna acción de responsabilidad podría prosperar. La víctima de un daño que no sea capaz de acreditar un tort específico estará inexorablemente desprovisto de cualquier reparación. Sin embargo, no todos los torts previstos suponen ilícito precontractual. Resulta necesario invocar el tort of deceit, que sanciona la infracción voluntaria o consciente (fraudulent misrepresentation $)^{18}$. Pero la posibilidad es bastante escasa y la prueba del dolo considerablemente difícil de llevar a cabo ${ }^{19}$. Sólo el tort of negligence que sanciona toda negligencia dañosa podría, por su relativa generalidad, resultar aplicable a la fase precontractual. Este tort sólo puede, sin embargo, ser alegado por la otra parte si quien lo pretende es deudor, a su vez, de una obligación particular de cuidado o diligencia (duty of care ${ }^{20}$. Los tribunales ingleses no reconocen sin embargo la existencia de tal duty of care con gran amplitud. En materia precontractual, la duty of care se aplica esencialmente a la parte que tiene una competencia particular sobre la que se funda el cocontratante $^{21}$.

6. Los sistemas jurídicos que reconocen un principio general de responsabilidad civil extracontractual se dirigen naturalmente hacia una calificación extracontractual de la responsabilidad precontractual. Esta concepción se respalda por jurisprudencia constante por parte de los tribunales de casación belgas y franceses ${ }^{22}$, pero también, por ejemplo, por la Corte de Casación italiana ${ }^{23}$. Ninguna consideración indemnizatoria ha sugerido aquí el recurso al contrato tácito, como sucedió por ejemplo en Derecho francés con las estipulaciones tácitas por terceros ${ }^{24}$.

${ }^{17}$ V. K. ZweigerT et H. KöTZ, An introduction to Comparative Law, 3th. ed. 1998, pp. 605 y siguientes.

${ }^{18}$ Derry v. Peek. (1889) 14 AC 337.

${ }^{19}$ V. O. Moreteau, Droit anglais des affaires, $1 .^{\text {a }}$ ed. Dalloz, 2000, n. 528.

${ }^{20}$ Donoghe v. Stevenson 1932 AC 562.

${ }^{21}$ V. Hedley Byrne \& Co. Ltd v. Heller \& Partners LTD 1963, 2, ALL ER 575, 1964 AC 465: responsabilidad de la banca que había ofrecido información errónea sobre la cuenta de uno de sus clientes basándose en la cual había actuado el demandante.

${ }^{22}$ V. B. DE CONINCK, «Le droit commun de la rupture des négociations precontractuelles» in Le processus de formations du contrat - Contributions comparatives et interdisciplinaires à l'harmonisation du droit européen. Op. cit. p. 17.

${ }^{23}$ V. p. ej. Cass. 16 juill. 2001, Giust civ mass. 2001, p. 1404 y stes; Cass. 29 abril 1999, n. ${ }^{\circ} 4299$, Giur. It. 2000 , p. 932 y siguientes.

${ }^{24}$ Cf. infra. n. ${ }^{\circ} 10$. 
En lo que hace al derecho inglés, hemos dicho que la vía a la responsabilidad extracontractual ha sido rechazada. A decir verdad, esta concepción no supone problemas especiales en la medida en que este derecho no acepta a priori sancionar la falta de respeto a las negociaciones. Resulta sintomática en esta materia la sentencia Walford $v$ Miles $^{25}$, en la que la Cámara de los Lores rechaza aceptar una obligación de buena fe en la negociación, debido a que esa obligación resultaría «incompatible con el antagonismo de las partes en la negociación». Sin embargo, los comportamientos precontractuales más reprobables no quedan siempre sin castigo. Algunos paliativos a esa situación se han desarrollado tanto en la esfera contractual como extracontractual, destacando entre ellos la noción del precontrato implícito (implied contract) o la teoría del estoppel.

La primera de esas soluciones ha sido ilustrada por el asunto Blackpool and Fylde Aero Club Ltd v Blackpool Borough Council ${ }^{26}$. El ayuntamiento de Blackpool realiza una licitación para la gestión de vuelos privados a partir de su aeropuerto, exigiendo que las ofertas llegaran antes de una fecha y hora determinadas. El demandante había presentado personalmente su oferta (tender) en el buzón del Ayuntamiento una hora antes del fin del plazo. Sin embargo, al no recoger el correo durante 24 horas, la oferta fue considerada extemporánea y descartada. La Court of Appeal estimó que la licitación redactada de ese modo supondría que el Ayuntamiento aceptaría analizar todas las ofertas que le llegaran antes de la fecha establecida. Dado que el demandante había aceptado la oferta de contrato (offer), el ayuntamiento habría incurrido en responsabilidad contractual no examinando por tardía la oferta (tender) realizada.

El estoppel, hoy en día consolidado en derecho francés ${ }^{27}$, es, de entrada, un principio procesal en virtud del cual una parte no puede contradecirse durante el proceso, existiendo en otro caso el riesgo de que puedan perjudicarle sus propias contradicciones siempre que la otra parte se haya fiado razonablemente de sus primeras declaraciones. El promissory estoppel es una prolongación de ese principio: si en razón de su comportamiento una parte A manifiesta su voluntad de comprometerse y la otra parte actúa de

25 (1992) 2 AC 128 (1992) 1 All ER 453, (1992) 2 WLR 174.

${ }^{26}$ (1990) 1 WLR 1195, (1990) 3 ER 25.

${ }^{27} \mathrm{~V}$. especialmente O. MonTREAU, L'estoppel et la protection de la confiance légitime, thèse, Lyon, 1990; B. FAuvarque-Cosson, «L'estoppel du droit anglais» in L'interdiction de se contredire au detriment d'autrui, Economica, 2001, p. 3; H. MuIR-WATT, «Pour l'accueil de l'estoppel en droit français» in Melanges Loussouarn, Dalloz, 1994, p. 303; D. MAZEAUD, «La confiance légitime et l'estoppel» RIDC 2006-2, p. 363. El estoppel no es ya en este momento una preocupación exclusivamente doctrinal, dado que la Cour de Cassation ha comenzado a aplicarlo (v. en materia de arbitraje internacional, Cass. 1 civ. 6 de julio de 2005, Bull. n. ${ }^{\circ} 302$, RDC 2006/4 p. 1279, note B. FAuverQue-Cosson). 
buena fe basándose en ese compromiso, A no podrá negar posteriormente la apariencia que ha creado. Sin embargo el promissory estoppel (como reminiscencia de su origen procesal) no puede ser invocado como base de una demanda sino tan sólo como defensa. No será posible recurrir a esta vía por tanto para obligar a cumplir sus obligaciones a los deudores recalcitrantes, sino que impedirá a quien ha cumplido retractarse de sus compromisos previos, si bien su compromiso no sería válido teniendo en cuenta los principios contractuales (particularmente por falta de consideration).

7. Estas soluciones son realmente creativas, pero no son comparables en eficacia a la responsabilidad extracontractual de los derechos francés e italiano y menos aún, como veremos, al alemán. Éste se ha dotado de una práctica muy eficaz contra los comportamientos desleales precontractuales. La reparación del daño puramente económico no es posible más que en circunstancias particulares enumeradas de modo exhaustivo ${ }^{28}$. Sin embargo, bajo la influencia de Jhering, que desde 1861 había desarrollado su célebre teoría de la culpa in contrahendo ${ }^{29}$, el BGB que entró en vigor en 1900 contenía varias disposiciones relativas a la indemnización del daño precontractual ${ }^{30}$.

Con el tiempo y la práctica la teoría se ha ido enriqueciendo al margen del BGB. La jurisprudencia ha identificado la existencia de una relación precontractual de obligación entre las partes de una negociación contractual. Esa relación, calificada a veces de «cuasi contractual», es un verdadero vínculo de confianza que da lugar a un cierto número de deberes u obligaciones cuya violación implica una responsabilidad para su autor. La jurisprudencia aplica así las reglas de la responsabilidad contractual y de ese modo se sanciona la ruptura intempestiva de las negociaciones por uno de los cocontratantes.

La ley de modernización del derecho de obligaciones de 26 de noviembre de 2001 (entrada en vigor el 1 de enero de 2002) ${ }^{31}$ supuso la entrada de las soluciones pretorianas en el BGB. Existe desde ese momento un $\S 311$ que responde al título «Relaciones de las obligaciones contractuales y extracontractuales» que prevé que esas relaciones pueden nacer no sólo de un contrato como tal, sino, igualmente, de las negociaciones previas ${ }^{32}$. No tiene relevancia que a esas relaciones se las denomine «cuasi contractuales» (en

28 V. W. Th. SCHNEIDER, «La codification d'institutions pretoriennes», RIDC 2002-4, p. 959 .

${ }^{29}$ V. Oeuvres Choisies, t. 1, 1969, p. 1 y siguientes.

${ }^{30}$ V. W. Th. Schneider, op. cit.; M. PedAmon, Le contrat en droit allemand, 2. a ed. LGDJ, 2004, n. ${ }^{\circ} 43$.

${ }^{31}$ Sobre esta ley, C. WITZ, «La nouvelle jeunesse du BGB insufflée par la reforme du droit des obligations», D. 2002, chon. P. 3156; M. SCHLEY, «La grande reforme du droit des obligations en Allemagne» D. 2002, chon. P. 1738.

${ }^{32} \mathrm{~V}$. la traducción propuesta por W. Th. SCHNEIDER. 
un sentido muy distinto del cuasi-contrato de los derechos francés o español). Conviene subrayar que estas relaciones se someten al mismo régimen que el de las obligaciones contractuales y particularmente, en lo que hace a su violación, a los $\S 280$ y siguientes del BGB. Asistimos por tanto en este sistema a una absorción del período precontractual por el régimen contractual, que encuentra su razón de ser en parte en la insuficiencia de respuestas aportadas por el sistema de responsabilidad extracontractual.

8. Debe subrayarse que las diferencias entre los sistemas no se encuentran solamente en las técnicas por ellos empleadas, sino especialmente en los objetivos pretendidos. Una tentativa de armonización de la materia no debería solamente establecer una distinción entre responsabilidad contractual y extracontractual; debería partir de la convicción de que es necesario por principio sancionar los comportamientos inadecuados en el nivel precontractual.

Las fuentes supranacionales son en este punto más próximas a los derechos continentales que al derecho ingles, en la medida en que afirman, en principio la existencia de una responsabilidad precontractual. Es la calificación de esta responsabilidad la que puede plantear interrogantes.

El artículo 2.15 de los principios Unidroit establece que «Las partes tienen plena libertad para negociar los términos de un contrato y no son responsables por el fracaso en alcanzar un acuerdo. Sin embargo, la parte que negocia o interrumpe las negociaciones de mala fe es responsable por los daños y perjuicios causados a la otra parte. En particular, se considera mala fe que una parte entre en o continúe negociaciones cuando al mismo tiempo tiene la intención de no llegar a un acuerdo». La existencia de un principio de responsabilidad precontractual no plantea por tanto duda alguna. Sin embargo el texto no precisa la naturaleza contractual o extracontractual de la citada responsabilidad. Podría considerarse que la presencia de este artículo en un texto dedicado a las relaciones contractuales responde de por sí a la cuestión planteada. Este argumento no resulta sin embargo decisivo ${ }^{33}$, en la medida en que el fundamento de la responsabilidad contemplada -la mala fe- no puede considerarse específicamente contractual.

En este sentido, los principios europeos aportan algunas aclaraciones. En la sección denominada «Responsabilidad derivada de las negociaciones», el artículo 2.301 retoma, perfeccionándolo, el artículo 2.15 de los citados principios Unidroit: «Las partes tienen libertad para negociar y no son responsables en caso de no llegar a un acuerdo. Sin embargo, la parte que hubiere negociado o roto las negociaciones de manera contraria a las exigencias de

${ }^{33}$ En el mismo sentido, H. MuIR WATT, «Les pourparlers: de la confiance trompée a la relation de confiance», in Les concepts contractuels français à l'heure des principes du droit européen des contrats, p. 53. 
la buena fe, será responsable de las pérdidas causadas a la otra parte. En especial es contrario a la buena fe que una parte entable negociaciones o prosiga con ellas si no tiene intención alguna de llegar a un acuerdo con la otra parte» ${ }^{34}$. Este precepto supone que la responsabilidad incurrida puede estar fundada en el dolo ${ }^{35}$. El comentario precisa que, «si bien en varios Estados miembros ese dolo implica responsabilidad extracontractual, serán de aplicación los principios respecto del mismo si afecta a una relación regulada por los Principios». La formulación resulta débil en la medida en que el dolo no interviene en el contrato sino antes de éste; es precisamente esta circunstancia la que hace suscitar dudas respecto de su calificación. Sin duda debe considerarse que la responsabilidad extracontractual está sometida a los principios en tanto que sea accesoria de un contrato que las partes plantean concluir. Esta fuerza de atracción del contrato se aborda en la introducción a los principios cuando se establece que «para decidir sobre las cuestiones que deberían ser tratadas en los principios, la Comisión ha adoptado un punto de vista funcional. Los principios contienen reglas que, en algunos sistemas, dependen del derecho de la responsabilidad extracontractual o los cuasi-contratos, aunque suponen un vínculo estrecho con los problemas de los contratos abordados» ${ }^{36}$. La fuente contractual o extracontractual de la obligación o del derecho desconocidos no resultan por tanto relevantes. Se plantea por tanto la cuestión de determinar hasta dónde puede llegar la integración en el contrato. Por ejemplo, ¿debe la obligación de reparación nacida de una falta precontractual ser regida por el régimen de las obligaciones contractuales? En lo que hace a la prescripción, los principios parecen admitirlo o al menos permitirlo, reconociendo a los artículos 14.101 y siguientes un ámbito de aplicación muy amplio ${ }^{37}$.

Desde el punto de vista de los autores de los Principios, esta extensión de su campo de aplicación se cohonesta difícilmente con las soluciones propias del derecho comunitario. Resulta conocido que, desde la Sentencia Taconi, de 17 de septiembre de $2002^{38}$, el Tribunal de Justicia de las Comunidades Europeas adoptó una postura radicalmente diferente. Es cierto que no pretendía limitar su intervención al contrato en sí puesto que pretendía dividir los ámbitos respectivos de la «materia contractual» y de la «materia extracontractual» en el sentido de la Convención de Bruselas de 27 de septiembre de 1968 sobre competencia judicial internacional y reconocimiento

${ }^{34}$ Muy próximos, pero aun más completos, v. art. 6 del Código Europeo de contratos (Proyecto Gandolfi).

${ }^{35}$ Punto VI.

${ }^{36}$ Punto III.

${ }^{37}$ Ver el comentario al artículo 14.101, punto IV: «El presente capítulo se aplica no sólo a las deudas contractuales sino igualmente a otras deudas».

${ }^{38}$ RCDIP 2003, pág. 678, nota P. RÉMY-CORLAY. 
y ejecución de sentencias en materia civil y mercantil. Presentada la cuestión prejudicial por parte de la Corte di cassazione italiana, el Tribunal decidió que «la acción por la cual la responsabilidad precontractual del defensor es invocada, puede considerarse materia extracontractual o cuasi extracontractual en el sentido del art. 5.3 de la Convención de Bruselas». Para llegar a tal conclusión, el Tribunal se basa, no sólo en la función reconocida a esa responsabilidad, sino en la fuente de las obligaciones no respetadas. El Tribunal recuerda que, de acuerdo con su jurisprudencia, la noción de materia contractual en el sentido del art. 5.1 de la Convención de Bruselas, no podría ser empleada en los casos en que no exista un acuerdo libremente adquirido por una de las partes respecto de la otra ${ }^{39}$. Ahora bien, en defecto de un acuerdo de este tipo «la obligación de reparar el perjuicio que resulta de una ruptura injustificada de las negociaciones no podría derivar más que de la violación de las normas jurídicas, especialmente de las que imponen a las partes la obligación de actuar de buena fe durante las negociaciones que llevan a la celebración de un contrato». Dado que la obligación violada no tiene su fuente en un contrato, la responsabilidad en que se incurre no puede ser contractual. No sólo el método seguido difiere del que siguen los Principios, sino que la violación del mismo deber general de buena fe conduce aquí a una responsabilidad extracontractual, mientras que allí se considera contractual.

\section{B. Fuera del acuerdo: los terceros}

9. Sólo las partes en el acuerdo de voluntades se consideran vinculadas por él y derivan de él derechos. Es el principio universal del efecto relativo del contrato ${ }^{40}$. En derecho francés, este principio se recoge en el artículo 1165 del Código Civil: «Los convenios no tienen efecto salvo entre las partes contratantes». En derecho inglés, se denomina ordinariamente por la jurisprudencia como privity of contract ${ }^{41}$. Aunque el BGB alemán no contiene un principio en que de manera solemne se recoja el principio, varias disposiciones no pueden ser entendidas más que a la luz del efecto relati$\mathrm{vo}^{42}$.

Son las excepciones a este principio las que implican una dificultad. Nos referiremos a dos de ellas: las estipulaciones por terceros y las acciones directas en los grupos o cadenas de contratos.

${ }^{39}$ TJCE 17 de junio de 1992, Jakob Handte, JCP 1992.II.21927, nota C. LARROUMET; RCDIP 1992, P. 726, nota H, Gaudemet TAllon; JDI 1993, p. 469, nota J; Bischoff; Rev. Trimestrielle de Droit Eur. 1992, p. 709 nota P. DE VAREILles SomMIERES; RTD Civ. 1993, p. 131, obs. P. JouRDAIN.

${ }^{40}$ V. K. ZWEIGERT et KöTZ, op. cit, p. 456, s.

${ }^{41}$ V. Tweeddle v. Atkinson, (1861) 1 B\&S 393; Dunlop Tyre Co, v. Selfridge (1915) AC 847.

${ }^{42}$ V. M. Pedamon, Le contrat en droit allemand, 2ème éd. LGDJ, 2004, n. ${ }^{\circ} 151$. 


\section{Las estipulaciones por terceros}

10. Verdadera excepción al principio del efecto relativo del contrato, la estipulación por terceros hace nacer un crédito a favor del tercero beneficiario. Éste dispone en derecho francés de una acción directa contra el oferente $^{43}$, que tiene su origen en el contrato concluido entre el oferente y el estipulante. Esto supone que el oferente puede oponer a los terceros beneficiarios las excepciones derivadas del contrato que habría podido oponer al estipulante. La materia es, por tanto, de naturaleza contractual, a pesar de la ausencia de contrato que vincule al oferente y al tercero beneficiario. El acuerdo de voluntades resulta existente, dado que el oferente debe por definición haber consentido a su obligación. Respecto del beneficiario, si bien su aceptación no es una condición para la estipulación de terceros ${ }^{44}$, resulta posible y convierte la estipulación en irrevocable ${ }^{45}$. El beneficiario se considera siempre libre de rechazar la estipulación de manera que no será ejecutada más que en caso de ser aceptada, aunque sea de modo tácito.

No resulta por tanto artificial explicar la relación de obligación oferente-beneficiario por un acuerdo de voluntades indirecto. No puede existir sin embargo en el caso de que el oferente no haya tenido conciencia del compromiso adquirido o cuando no lo conocía. Es el caso de que el juez identifique en un contrato una estipulación por tercero tácita o implícita. Tales estipulaciones se preveían originariamente en los contratos de transporte de mercancías y posteriormente se extienden a los contratos de transporte de personas. Aunque la teoría de los grupos de contratos no estaba desarrollada, el juez francés vio la posibilidad de acordar una acción contractual a la víctima de un daño contractual sin violar abiertamente el principio del efecto relativo del contrato. Es el caso, por ejemplo, de una persona que fallece en el curso de un transporte ferroviario; a fin de acordar a sus herederos una acción contractual que les permita prevalerse de las obligaciones de seguridad del transporte, el juez incluye en el contrato de transporte una cláusula tácita en su beneficio $^{46}$. La Cour de cassation francesa no ha abusado de ese artículo, de hecho en retroceso en el ámbito del transporte ${ }^{47}$. Se continúa, sin embargo, realizando un uso episódico d éste ${ }^{48}$.

${ }^{43}$ Cass. Civ. 16 enero 1888, DP, 1888, 1.77.

${ }^{44}$ Cass. 1 civ. 19 diciembre 2000, bull, n. ${ }^{\circ} 333$.

${ }^{45}$ C. civ. Art. 1121 , in fine.

${ }^{46}$ V. p. ej. Cass. $1^{\text {o }}$ civ. 15 febrero 1955 D. 1955.519.

${ }^{47}$ V. descartando la estipulación a favor de terceros en beneficio de las víctimas por referencia ya que, dado que éstos no actuan en calidad de cesionarios ni herederos, no podrían suceder a sus padres fallecidos. Cass. 1. ${ }^{\circ}$ civ. 28 de octubre 2003, Bull, n. ${ }^{\circ} 219$.

${ }^{48} \mathrm{~V}$. especialmente, en materia de contaminación de transfusiones sanguíneas, Cass. 1. ${ }^{\circ}$ civ. 14 de noviembre de 1995 Bull. n. $^{\circ} 414$. 
11. Esta extensión del ámbito de la responsabilidad contractual no encuentra fácilmente eco en el derecho comparado. La estipulación a favor de terceros se ha aplicado con profusión con formas diversas ${ }^{49}$. Ciertos sistemas son, sin embargo, refractarios a la admisión de una estipulación a favor de terceros meramente tácita. Tomaremos como ejemplo el sistema inglés ${ }^{50}$.

El principio del efecto relativo del contrato (privity of contract) resulta de aplicación muy restrictiva en el sistema inglés ${ }^{51}$. Como sucede habitualmente, este principio se expresa de manera procesal: el tercero carece de acción fundada en un contrato del que no es parte ${ }^{52}$. Cabe la posibilidad de realizar estipulaciones por terceros, pero el juez no obligará al oferente a respetar la promesa ${ }^{53}$. El compromiso estará desprovisto de consideration en la medida en que el beneficiario no aporte una contrapartida a su acuerdo. Este rigor puede obstaculizar algunas operaciones muy útiles para la sociedad moderna. Por esta razón esta situación ha sido objeto de críticas severas y los juristas ingleses han tratado de evitar su aplicación suponiendo trusts tácitos (el contratante se convertiría en un trustee deudor de la obligación a favor de terceros) o recurriendo a la representación (el estipulante sería el representante del beneficiario en nombre del cual contrataría obteniendo el acuerdo del oferente $)^{54}$. Estas soluciones no son sino artificios poco satisfactorios y varios autores subrayan el aislamiento del derecho inglés no sólo respecto del Derecho de la Unión Europea, sino incluso respecto del derecho del Common Law, dado que la estipulación a favor de tercero ha sido aceptada tanto en derecho americano o australiano ${ }^{55}$.

En esas circunstancias se ha adoptado en 1999 la Contracts (Rights of third parties) Act, que autoriza a los contratantes a conferir a terceros derechos que pueden ser exigidos procesalmente. Debe decirse, sin embargo, que el reconocimiento de la estipulación de terceros ha sido, voluntariamente ${ }^{56}$, muy reservada. La ley (Section 1) exige que la estipulación sea expresa y que

${ }^{49}$ W. K. ZWEIGERT y H. HöTZ, op. cit. loc cit.

${ }^{50}$ V. H. BeALE, «Stipulations for third parties in English Law», Mélanges Ghestin, p. 45 .

${ }^{51}$ V. en general G. H. TReitel, op. cit. p. 582.

52 Tweedls v. Atkinson (1861) 1 B\&S 393; Dunlop Tyre Co v. Selfridge (1915) AC 847.

${ }^{53}$ V. Beswick v. Beswick, (1968) AC 58: un tío había cedido su empresa a su sobrino, que se había comprometido a emplear a su tío para el resto de sus días por un salario determinado. Se había comprometido igualmente, en caso de fallecimiento de su tío, a entregar a su viuda 5 libros semanales hasta su muerte. El deudor no cumplió sus obligaciones respecto de su tío y paralizó su obligación respecto a su tía inmediatamente después del fallecimiento de su tío. La sentencia determina que la viuda no está en posición de exigir personalmente el cumplimiento del contrato en la medida en que no es parte en él.

${ }^{54}$ V. H. BEALE, op. cit. p. 50.

${ }^{55}$ K. ZWEIGERT y H. HÖTZ, op. cit. p. 466.

${ }^{56}$ V.H. BEALE, op. cit. p. 58. 
los terceros beneficiarios sean expresamente identificados en el contrato. Esto supone que muchas de las situaciones que darían lugar a reconocimiento de un derecho de terceros en derecho francés, quedan necesariamente fuera de la esfera contractual en derecho inglés. No resultaría posible, por ejemplo, contractualizar la responsabilidad de un centro de transfusión sanguínea respecto de un trasfundido ${ }^{57}$-en la medida en que la ausencia de una estipulación expresa, impide recurrir a las acciones directas como en derecho francés ${ }^{58}-$.

12. Teniendo en cuenta la gran diferencia existente entre los sistemas analizados, cabría cuestionar la eficacia del artículo 6.110 de los principios de derecho europeo de los contratos, que admite la estipulación por terceros no sólo cuando existe una disposición expresa, sino también cuando se deduce del objetivo del contrato o de las circunstancias del caso. Según el mismo texto no es necesario que los terceros sean identificados en el momento de la estipulación. Esta disposición es totalmente contraria al derecho positivo inglés; sin duda va más allá de lo que admite el derecho francés que, tal como hemos determinado, no admite más que de modo tangencial las estipulaciones tácitas. El proyecto Gandolfi resulta más neutro al admitir las estipulaciones en favor de terceros no identificados, pero no permite la forma tácita ${ }^{59}$.

En definitiva, la dificultad estriba en la determinación de la existencia de las estipulaciones tácitas de la voluntad de las partes. El problema sería otro en el caso de que se tratara de afirmar que la acción reconocida a los terceros es un efecto objetivo del contrato. Es la solución seguida por el Bundesgerichtshof alemán, a través de la institución del «contrato con efecto protector para los terceros» (vertrag mit Schutzwirkung für Dritte) ${ }^{60}$. Igual que la estipulación tácita a favor de terceros del derecho francés, esta institución permite conferir a las víctimas de una mala ejecución de un contrato una acción contractual. Igual que en derecho francés, son las lagunas de la responsabilidad extracontractual -más evidentes quizá en el derecho alemán ${ }^{61}$ - las que han convertido esta construcción en necesaria. Pero, a diferencia de lo que sucede en la estipulación a favor de tercero, la protección acordada a los terceros es un efecto objetivo del contrato. Este efecto no depende de la voluntad de las partes, sino de las circunstancias objetivas: la exposición de los terceros a las consecuencias de la inadecuada ejecución (criterio de la proximi-

${ }^{57}$ Op. cit., p. 60.

${ }^{58}$ Cf. infra, n. ${ }^{\circ} 14$.

${ }^{59}$ V. Código Europeo de contratos, art. 72.

${ }^{60}$ V. M. PEDAMON, op. cit., n. ${ }^{\circ} 159$; P. ANCEL, «Le contrat avec effets protecteurs pour les tiers», RDC 2004, p. 471.

${ }^{61}$ En ese sentido, P. ANCEL, op.cit., p. 474. 
dad); el interés de los contratantes en la protección de los terceros; la posibilidad para el deudor de prever el riesgo de causar daños a terceros; la necesidad de proteger específicamente a los terceros, lo que supone que no dispone de una acción de reparación. Si históricamente se ha tratado de explicar esta creación jurisprudencial por la vía de la estipulación implícita a favor de terceros, el fundamento parece hoy en día superado ${ }^{62}$.

En la medida en que tan sólo se trata de forzar el contrato y en la medida en que la misma práctica es reconocida en todos los sistemas jurídicos ${ }^{63}$, la experiencia alemana podría ser más federadora que el artículo 6.110, previamente citado, de los principios de derecho contractual europeo ${ }^{64}$. Sin embargo, en el estado actual del derecho comparado, esta solución no es sino un obstáculo a una definición uniforme de la materia contractual.

\section{Acciones directas}

13. ¿Más allá de la estipulación a favor de tercero, pueden existir acciones de carácter contractual entre dos personas que no son parte de un mismo contrato? Para el jurista francés esta cuestión está íntimamente relacionada con la admisibilidad de las acciones directas. Es más, es preciso subrayar que esta expresión comprende al menos dos tipos de realidades muy diferentes: la acción directa de pago (por ejemplo, la que tiene el asegurador contra el autor del daño ${ }^{65}$ ) y la acción directa de responsabilidad (la que posea el jefe de obra contra el subcontratista). Además, si determinadas acciones directas han sido creadas por la jurisprudencia, otras tienen su origen en la ley. En este último caso, es la norma que las crea quien suele determinar su régimen jurídico, de manera que no hay ningún interés práctico en la discusión de su naturaleza contractual o extracontractual.

Por lo tanto, nos centraremos en el supuesto de acciones directas diseñadas por los jueces en el supuesto de grupos de contratos. En Derecho francés la calificación de la acción no depende de que el conjunto de contratos conlleve o no la transmisión del derecho de propiedad. Si el conjunto de contratos es traslativo del derecho de propiedad, la acción directa es necesariamente contractual. Éste es el caso de la acción directa reconocida al subadquirente contra el fabricante o al vendedor intermediario por los vicios ocultos que afectan a la cosa vendida ${ }^{66}$, o incluso de la acción que tiene el jefe de obra contra el fabricante de los materiales utilizados por el empresario ${ }^{67}$. La cali-

\footnotetext{
${ }^{62}$ P. ANCEL, op.cit., p. 475.

${ }^{63}$ Pero con motivaciones y fundamentos a veces diferentes: cf. infra, n. ${ }^{\circ} 22$ a 24 .

${ }^{64}$ V. P. ANCEL, op.cit., p. 481, proponiendo inspirarse para una renovación del derecho francés formalmente próximo al artículo 1135 del Código Civil.

${ }^{65}$ Código de seguros, art. L.124-3

${ }^{66}$ Cas. lère civ., 9 octubre 1979, Bull. N. ${ }^{\circ} 241$.

${ }^{67}$ Cass. ass. Plén., 7 febrero 1986, Bull. n. ${ }^{\circ} 2$.
} 
ficación contractual de la acción directa viene determinada por el hecho de que ciertos derechos y acciones están ligados a la cosa transmitida y se transmiten con ella incluso cuando existe un cambio de propietario. Algún sector doctrinal trae a colación la noción del intuitus rei. Por el contrario, si el grupo de contratos no tiene como efecto la transmisión de la propiedad, la acción directa eventualmente reconocida a una de las partes es extracontractual ${ }^{68}$. En este caso, prevalece el principio del efecto relativo del contrato.

El principio de la distinción entre acciones directas contractuales y acciones directas extracontractuales -intuitus rei- es tan poco convincente que la calificación de estas acciones directas ha motivado divergencias sistemáticas entre la primera y la tercera sala civil de la Cour de cassation, hasta el punto de haber sido necesaria la intervención de la Assemblée plénière para unificar la jurisprudencia. ¿Cómo es posible admitir una acción de carácter contractual entre dos personas que no han prestado previamente su consentimiento por el mero hecho de que, en momentos diferentes, han sido propietarias de una misma cosa? Esto hace que, en la calificación de lo que se considera materia contractual, el acuerdo de voluntades pase a un segundo plano, por detrás del objeto del contrato.

¿Cuál será en este punto la aportación del Anteproyecto de reforma del derecho de las obligaciones? Es difícil responder a esta pregunta. Según la redacción propuesta del artículo 1168 «Algunos acreedores están facultados por la ley para reclamar directamente el pago de su crédito al deudor de su deudor, con el límite del importe del derecho de crédito. La acción directa está igualmente permitida en la medida en que permite evitar el empobrecimiento injusto del acreedor, teniendo en cuenta el nexo que une los contratos». Es decir, únicamente se contempla la acción directa de pago. El precepto mencionado figura en la sección titulada «Del efecto de los convenios frente a terceros», lo que, al hacer de la acción directa un efecto del contrato concluido por su beneficiario, parece abocar a reconocerle una naturaleza contractual. Sin embargo, la referencia a la ley y el doble límite impuesto por el artículo parece contradecir esta primera lectura. Por otro lado, el segundo párrafo parece estar inspirado por otro fundamento: el enriquecimiento injusto del acreedor. El empobrecimiento injusto de uno es la contrapartida del enriquecimiento injusto del otro. Es criticable que el Anteproyecto, en la medida en que pretende regular la acción directa dentro del Código Civil, no despeje las dudas sobre una cuestión que suscita tantos interrogantes.

14. El Derecho inglés se muestra en principio hostil a la admisión de las acciones directas. En realidad, la noción misma de grupo de contratos es contraria al principio de la privity of contract.

${ }^{68}$ Cass. ass. Plén., 12 julio 1991, Bull. n. ${ }^{\circ} 5$. 
El Derecho inglés carece de un equivalente a la garantía por vicios ocultos del Derecho francés. Sin embargo, el vendedor profesional está obligado a entregar unos bienes de calidad satisfactoria y que sean aptos para el uso particular al que están destinados ${ }^{69}$. Sin embargo, esta garantía únicamente se le otorga al primer comprador: los sucesivos adquirentes carecen de toda acción contra el vendedor inicial. Cada uno de ellos debe actuar contra su propio vendedor, que repetirá contra el suyo y así sucesivamente ${ }^{70}$.

A fortiori, la ausencia de una cadena de ventas sucesivas excluye la posibilidad de ejercitar la acción directa. El ejemplo típico es el de un grupo de contratos que tiene por objeto la construcción de un edificio. En este caso, no se reconoce ninguna acción directa de pago al subcontratista contra el jefe de obra; ni tampoco acción de responsabilidad al jefe de obra contra el subcontratista. En principio, el demandante únicamente tiene abierta la vía extracontracutal, a menos que el juez considere que entre el vendedor y el subadquirente o entre el jefe de obra y el subcontratista existe un contrato accesorio (collateral contract).

El concepto de collateral contract está muy bien ilustrado por el asunto Shanklin Pier Ltd v. Detel Products Ltd ${ }^{71}$. Una sociedad portuaria, que había contratado a un profesional para pintar sus instalaciones, contactó con un fabricante de pinturas para interesarse por la calidad de sus productos. Ante la garantía de seis años que el fabricante de la pintura le ofreció, ordenó al pintor el uso de este concreta marca de pintura. Sin embargo, la pintura se deterioró en tres meses, lo que motivó la acción contractual de la sociedad portuaria contra el fabricante. Efectivamente, el fabricante de pinturas se había comprometido contractualmente a garantizar la calidad de sus productos como contrapartida (in consideration) a la orden de comprar el producto defectuoso que la sociedad había dado a su jefe de obra. Este mismo razonamiento permitiría al jefe de obra ejercitar una acción contra el subcontratista, desde el momento en que ambas partes están unidas por un collateral contract. Es el supuesto en el que el subcontratista, que ha contratado con el empresario principal, es elegido sin embargo por el jefe de obra ${ }^{72}$. Esta elección conlleva una consideration suficiente con el contrato del subcontratista $^{73}$.

${ }^{69}$ Sale of Goods Act 1979, Section 14.

${ }^{70}$ Sucede lo mismo en el marco del régimen jurídico instaurado por la directiva europea n. ${ }^{\circ}$ 1999/44 de 25 de mayo de 1999 sobre determinados aspectos de la venta y garantías de los bienes de consumo (traspuesta por la Sale and Suply of Goods to Consumers Regulations 2002). El consumidor comprador carece de acción directa contra su vendedor, quien puede ejercitar una acción contra el productor.

${ }^{71}$ [1951] 2 KB 854.

${ }^{72}$ V. Los ejemplos propuestos por G. H. TReITEL, op. cit., p. 583.

${ }^{73}$ Op. cit., p. 584. 
15. Vemos por lo tanto que los argumentos esgrimidos por la jurisprudencia francesa y la inglesa para reconocer al demandante la acción contractual son muy diferentes. Mientras que el juez francés se limita a constatar si existe un grupo de contratos con un objeto común, su homólogo inglés centra la atención en la voluntad individual, única fuente generadora de obligaciones de carácter contractual. Posiciones tan contrapuestas constituyen un serio obstáculo para el éxito de cualquier tentativa de armonización de los derechos nacionales en la materia. Ello explica sin duda el silencio de los Principios de Derecho Europeo de los Contratos al respecto ${ }^{74}$. ¿Implica ello que los Principios son inaplicables en este caso? Esta interpretación facilitaría sin duda su inserción en el derecho positivo europeo. En efecto, el TJCE ha afirmado que la materia contractual «no debe ser interpretada en el sentido de entender como tal una situación en la que no existe un compromiso libremente asumido entre las partes», de donde parece inferirse que la acción directa del subadquirente contra el vendedor original no es contractual ${ }^{75}$. Sin embargo, esta solución debe ser interpretada restrictivamente puesto que únicamente interpreta el alcance de la noción «materia contractual» en el sentido del artículo 5.1 de la Convención de Bruselas de 27 de septiembre de 1968 relativo a la competencia judicial y al reconocimiento y ejecución de resoluciones judiciales en materia civil y mercantil. De hecho, el mismo TJCE ha afirmado que se trata de una noción autónoma que debe ser interpretada «teniendo en cuenta principalmente el sistema y los objetivos de la propia Convención» ${ }^{76}$. Por lo tanto, no debe descartarse que el concepto «materia contractual» reciba una interpretación diferente según el texto internacional que deba interpretar el tribunal europeo. Así las cosas, no parece apropiado que el TJCE no requiera siempre la presencia de un elemento tan fundamental como puede ser la voluntad del contratante.

De la misma manera, cuando el derecho comunitario ha reconocido al subadquirente de un producto defectuoso una acción directa contra el fabricante, ha preferido no hacerlo en el ámbito contractual. En la mayor parte de las ocasiones existe lo que el Derecho francés denomina una cadena de contratos formada por un conjunto de ventas sucesivas, puesto que se hace extraño imaginar que un consumidor adquiera directamente el producto del fabricante. Sin embargo, la directiva de 25 de julio de 1985 no contempla esta calificación: ella crea una acción de responsabilidad desconocida e inédita, ni contractual, ni extracontractual, ya que en este punto, una vez más, hubiera sido difícil armonizar los diferentes derechos nacionales, tan divergen-

${ }^{74} V$. en el mismo sentido, $\mathrm{Ph}$. DIDIER, «El efecto relativo», en Les concepts contractuels français à l'heure des principes du droit européen des contrats, Dalloz, col. Thèmes et commentaires, 2003, p. 187.

${ }^{75}$ Asunto Handte cit., supra, nota 39.

${ }^{76}$ TJCE 8 marzo 1988, Arcado cit., supra, nota n. ${ }^{\circ} 4$. 
tes al respecto. Por lo demás, la directiva declara que no atenta contra los diferentes regímenes internos de responsabilidad existentes, a los que no hace sino añadir una nueva acción ${ }^{77}$. La directiva 44/1999, de 25 de mayo de 1999, sobre determinados aspectos de la venta y garantías de bienes de consumo prevé la posibilidad de reconocer una responsabilidad directa del productor en caso de un defecto de conformidad del producto que le fuera imputable ${ }^{78}$. Se puede pensar que esta acción tendrá la misma naturaleza híbrida -ni contractual ni extracontractual- que la anterior.

\section{El acuerdo incierto}

16. El proceso de negociación presenta una doble ventaja: por un lado, muestra la voluntad de las partes de llegar a un acuerdo; por otra, indica que este acuerdo es el origen de un contrato futuro. Ante la ausencia de negociaciones, se puede dudar de la realidad del acuerdo al que pretendidamente se ha llegado. Si el acuerdo no ha sido precedido de unas negociaciones, no es fácil saber si tiene una naturaleza contractual o no. Ante la ausencia de toda negociación, los interesados pueden llegar a un acuerdo sin que deseen conferirle el valor de un contrato.

Sólo dos categorías de negocios jurídicos escapan, en principio, a estas dificultades: los contratos reales y los contratos formales. En principio, la formación (o la ausencia de formación) de estos contratos es siempre cierta. Y el consensualismo, principio sobre el que se asientan la mayor parte de sistemas jurídicos occidentales ${ }^{79}$, explica ampliamente el problema de la delimitación de las fronteras del contrato: si el respeto a las reglas de forma se había exigido siempre ad validitatem, sería suficiente con constatar la ausencia de forma para colocarse fuera del ámbito contractual y viceversa.

\section{Incertidumbre sobre la existencia misma del acuerdo}

17. Hay un determinado número de situaciones que no debieran plantear dificultad alguna: aquellas que el derecho positivo ha tenido el cuidado de vincular a la categoría de los cuasicontratos. Por ejemplo, podemos dudar a priori de la calificación que merece una situación en la que una persona gestiona los asuntos de otra sin que ésta lo haya consentido expresamente. La calificación es aún más delicada si se comprueba que el administrado ha tenido conocimiento de la gestión en curso porque pueden concurrir los pre-

\footnotetext{
${ }^{77}$ Art. 13, traspuesto al art. 1386-18 del Código civil.

${ }^{78}$ Considerando 23 y art. 12.

${ }^{79}$ V. H. Kötz y A. FLesSner, European Contract Law, vol. I, Formation, Validity and Content of Contracts; Contracts and Third Parties, Clarendon Press, 1997, p. 78.
} 
supuestos necesarios para hablar de consentimiento tácito. Esta hipótesis está contemplada en el Derecho francés por la gestión de negocios ajenos, uno de los dos cuasi-contratos regulados por el Código Civil. Sabemos igualmente que el conocimiento de la gestión por el administrado es indiferente ${ }^{80}$.

A decir verdad, a pesar de su nombre, los cuasicontratos no tienen nada de contractual. Como dice el artículo 1371 del Código civil, proceden de un hecho puramente voluntario -unilateral- y no de un intercambio de consentimientos ${ }^{81}$. Desde la óptica del derecho inglés, quizás fuera preferible hablar de un derecho de la restitución (Law of Restitution) a hablar de cuasicontratos. En cualquier caso, en derecho francés la frontera tradicional entre el contrato y el cuasicontrato es bastante neta, lo que se explica por el hecho de que la categoría de los cuasicontratos es muy restringida y bastante estable.

Al menos así lo era, hasta que la Cour de cassation descubrió en el artículo 1371 del Código civil las posibilidades que le habían sido ya proporcionadas en otro ámbito por el artículo 1384, párrafo primero, del código. Apoyándose sobre un texto que a priori no tenía otro valor que el de mera introducción a las disposiciones que le siguen, el tribunal ha diseñado los contornos de una categoría general, no limitada a las tres figuras clásicas -pago de lo indebido, gestión de negocios ajenos y enriquecimiento sin causa-. Esta jurisprudencia surgió principalmente por su aplicación al problema de las loterías publicitarias ${ }^{82}$. Los hechos son los siguientes: una persona recibe de una sociedad de venta por correspondencia dos documentos que le designan, de forma nominativa, repetitiva y en mayúsculas, como ganador de una importante suma de dinero, con la única condición de reenviar en un determinado margen de tiempo un recibo de validación que se le adjunta. El destinatario firma y envía por correo la documentación en cuestión, pero jamás recibe el premio que le había sido prometido, ni ninguna otra respuesta. La Cour d'appel de París considera que la sociedad ha cometido una falta extracontractual por la creación de la ilusión de ganar un premio importante. Pero para la Cour de cassation, la situación es, en realidad, cuasicontractual y el «organizador de un sorteo que anuncia un premio a una persona

${ }^{80}$ C. civ., art. 1372: «Cuando una persona gestionara voluntariamente el asunto de otra, bien que el propietario conociera la gestión, o bien la ignorara, el que gestione contraerá la obligación tácita de continuar la gestión que comenzó...». Algunos autores consideran que en la medida en que el propietario ha tenido constancia de este hecho y no se ha opuesto, presta su consentimiento y se forma un contrato. V. R. Bout, La gestion d'affaires en droit français contemporain, LGDJ, 972, n. $^{\circ} 283$ y ss.

81 «Los cuasicontratos son los hechos puramente voluntarios de la persona, de los que resulta una obligación cualquiera frente a un tercero, y algunas veces una obligación recíproca entre las dos partes».

${ }^{82}$ Vid. Cass. Com. 26 octobre 1999, Bull. n. ${ }^{\circ} 193$. 
con nombre y apellidos sin poner en evidencia la existencia de una condición se obliga, por ese mero hecho voluntario, a entregárselo» ${ }^{83}$.

Sorprende la calificación dada: el anuncio «meramente voluntario» no puede carecer de consecuencias jurídicas, de manera que no es artificial considerar que la sociedad de venta por correspondencia ha emitido una oferta de contrato, oferta que ha sido aceptada por el destinatario. Éste era, por otra parte, el estado de la jurisprudencia francesa anterior a la sentencia citada ${ }^{84}$. Sin embargo, algún sector doctrinal ha defendido que, dada la ausencia de voluntad real de obligarse, el premio no podía ser considerado como una verdadera oferta ${ }^{85}$. Esta perspectiva contractual ante una situación análoga es sostenida por el Tribunal de Justicia comunitario en el asunto Rudolf Gabriel $^{86}$. El Tribunal, en interpretación de la Convención de Bruselas de 27 de septiembre de 1968, ha afirmado que «la acción jurisdiccional mediante la cual un consumidor pretende que se condene, en el Estado contratante en cuyo territorio tiene su domicilio y en virtud de la legislación de este Estado, a una sociedad de venta por correo establecida en otro Estado contratante a entregarle un premio, cuando dicha sociedad le había remitido personalmente una comunicación por la que podía darse la impresión de que se le atribuiría un premio si realizaba un pedido de mercancías por un importe determinado y este consumidor realizó efectivamente tal pedido sin que se le entregara dicho premio, es una acción en materia de contratos en el sentido del artículo 13, párrafo primero, número 3, de dicho Convenio» ${ }^{87}$. A diferencia del asunto resuelto en Francia, el Sr. Gabriel no podía recibir el premio a menos que hiciera un pedido. Bajo estas condiciones, es fácil concluir que una vez se ha efectuado el pedido se ha concluido un contrato en el que el pago del premio prometido no es más que una prestación accesoria ${ }^{88}$. Sin embargo, el Tribunal establece que el Sr. Gabriel ha concluido el contrato de compraventa de mercancías esencialmente, si no exclusivamente, como consecuencia de la proposición del vendedor en la que figuraba una promesa de un premio de un valor notablemente superior al importe mínimo exigido para el pedido ${ }^{89}$ e insiste además sobre el hecho de que el consumidor ha acepta-

${ }^{83}$ Cass. Ch. Mixte 6 septiembre 2002, Bull. n. ${ }^{\circ}$ 4; D. 2002, AJ p.2531 obs. A. LeINHARD e informe M. GRIDEL; D. 2002, Jur. P. 2963, nota D. MAZEAUD; JCP E 2002 n. ${ }^{\circ} 1687$, p. 1869, nota G. VINEY; Defrénois 2002, n. ${ }^{\circ} 37644$, p. 1608, nota E. SAVAuX; Contrats-Concurrence-Consommation, déc. 2002, Chron. P. 4, nota Ph. Le Tourneau y A. Zabala; Gax. Pal. 19 febrero 2003, n. ${ }^{\circ} 50$ a 51, Jur., pp. 30-32, nota M.-L. NiBOYET.

${ }^{84}$ Cass. 2ème civ., 11 febrero 1998, Bull. N. ${ }^{\circ}$ 55; D. 1999, Somm. P. 109, obs. R. Libchaber; JCP G 1998.II.10156, nota G. CARducCI; Defrénois 1998, p. 1044, obs.

D. MAZEAUD.

${ }^{85} \mathrm{~V}$. El informe del Conseiller GRIDEL, cit. nota 58.

${ }^{86}$ TJCE 11 julio 2002, asunto C-96/00, RCDIP, 2003, p- 484, nota P. RÉMY-CoRLAY.

${ }^{87}$ Punto 60.

${ }^{88}$ V. Punto 48.

${ }^{89}$ Punto 54. 
do en su conjunto la proposición del profesional ${ }^{90}$. Un último análisis que es determinante es el intercambio de consentimientos efectuado ${ }^{91}$. La existencia del consentimiento es más importante que el objeto (una compraventa de mercancías o la entrega de un premio). Por lo tanto, no debiera ser diferente en el supuesto en que la reclamación del premio no fuera acompañada de la realización del pedido.

La calificación contractual puede incluso encontrar su fundamento en el artículo 2.107 de los Principios Europeos, según el cual «la promesa que pretende ser jurídicamente obligatoria sin aceptación vincula a su autor». Los ejemplos que nos encontramos en el comentario no son solamente los relativos a las ofertas publicitarias. También encontramos «hechos puramente voluntarios», según la expresión empleada por la jurisprudencia francesa ${ }^{92}$. Y si el tenor literal del artículo no es suficientemente claro, el comentario precisa que las promesas obligatorias sin aceptación «deben ser consideradas como contratos, con todas las particularidades que les son inherentes $»^{93}$.

Sin duda inexacto, el análisis de la Cour de Cassation francesa es difícilmente conciliable con los diferentes derechos europeos, que carecen de una concepción amplia del cuasicontrato ${ }^{94}$. Por ejemplo, el Código Civil italiano no dispone de una norma general comparable a la del artículo 1371 del Código Civil francés. En él no se reagrupan a los tres cuasicontratos clásicos en una misma sección: la gestión de negocios ajenos (arts. 2028-2032), el pago de lo indebido (arts. 2033-2040) y el enriquecimiento sin causa (arts. 2041-2042) son objeto de títulos diferentes del código italiano. Como se verá más adelante, el enriquecimiento sin causa tiene su origen en la ley, lo que no sucede en el caso francés ${ }^{95}$. No obstante, y aunque los tres cuasicontratos reciban un tratamiento diferente, todos tienen en común la existencia de un enriquecimiento jurídicamente inexplicable al que el Derecho debe dispensar una solución. Ahora bien, el mismo obstáculo, prácticamente idéntico, aparece en el Derecho alemán e, incluso, en el derecho inglés, estando los dos estrechamente vinculados a la exigencia de un enriquecimiento sin cau$\mathrm{sa}^{96}$.

\footnotetext{
${ }^{90}$ Puntos 48 y 54.

${ }^{91} V$. sobre esta constante del Derecho comunitario, R. ScHulze, «Des principes de la conclusion du contrat dans l'acquis communautaire», RIDC, 2005-4, p. 877.

${ }^{92} \mathrm{~V}$. la promesa unilateral de constituir un fondo de ayuda para las viudas e hijos de los soldados muertos en la guerra del Golfo, ilust. n. ${ }^{\circ} 1$.

${ }^{93}$ Sobre esta disposición y su aplicación a las loterías publicitarias, A. BugADA, en Regards croisés sur les principes du droit européen du contrat et sur le droit français, PUAM, 2003, p. 182.

${ }^{94}$ En el mismo sentido, P. Remy-CoRlay, nota cit.

${ }^{95}$ Sin embargo, figura en el Anteproyecto Catalá de reforma del derecho de las obligaciones, en los artículo 1336 a 1339.

${ }^{96}$ P. REMY-CORLAY, nota cit.
} 
18. En el supuesto anterior, la existencia de un contrato parece dudosa puesto que la declaración emitida por una de las partes no constituye de forma evidente una oferta de contratar. Aunque existe la apariencia de contrato, la intención de las partes de vincularse contractualmente no es cierta. Es sabido que el Derecho francés está más vinculado a la intención de las partes que a su intención aparente ${ }^{97}$. Ahora bien, en este punto mantiene una postura minoritaria. A excepción del Derecho belga que comparte el objetivismo del Derecho francés ${ }^{98}$, la mayor parte de los ordenamientos vecinos comparten una concepción eminentemente objetiva de la voluntad ${ }^{99}$.

En este punto hay que traer a colación el artículo $\$ 116$ del BGB, que parece estar diseñado a medida para los supuestos de los sorteos publicitarios. Este precepto establece que la declaración de voluntad «no es nula por el mero hecho de que su autor se reserve para sí su intención de no vincularse por lo que declara» ${ }^{100}$. Se trata, evidentemente, de proteger la confianza que cada persona deposita en las declaraciones de voluntad de los demás. Pero, en cualquier caso, es necesario que la proposición tenga una apariencia de seriedad: la oferta hecha para complacer no vincula contractualmente a su autor puesto que es simplemente nula ${ }^{101}$.

El Derecho inglés prima también la apariencia sobre la voluntad real. No hay contrato sin intención de obligarse (intention to create legal relations) -lo que permite, tal y como sucede en el Derecho alemán, rechazar las declaraciones no emitidas con seriedad ${ }^{102}$-. Pero la intención de contratar es apreciada objetivamente, según la apariencia creada por cada parte contratante ${ }^{103}$. En apoyo de esta afirmación se suele citar el asunto Smith v Hugues ${ }^{104}$, aunque existen otras resoluciones que son igualmente significativas. Por ejemplo, en el asunto Carlill v Carbolic Somke Ball Co. ${ }^{105}$, un laboratorio se había comprometido, a través de la prensa, a entregar la suma de cien libras

${ }^{97}$ Como ejemplo, el artículo 1156 C.C.: «en los contratos debe estarse a la intención común de las partes contratantes, más que al tenor literal de sus cláusulas».

${ }^{98}$ V. C. DELForge, «La formation des contrats sous un angle dynamique - Réflexions comparatives» en Le processus de formation du contrat - Contributions comparatives et interdisciplinaires à l'harmonisation du droit europèen, op. cit. p. 139.

${ }^{99}$ V. P. REMY-CORLAY, nota cit. del mismo autor, «L'existence du consentement», en Les concepts contractuels français à l'heure des principes du droit europèen des contrats, op. cit. p. 29. En particular, para una comparación franco-alemana, A. RIEG, Le rôle de la volonté dans l'acte juridique en droit civil français et allemande, LGDJ, 1961.

${ }^{100}$ Traducción de M. PeDAmon, Le contrat en droit allemand, op.cit.

$101 \S 118$ BGB: «Es nula toda declaración de voluntad que no tenga un fin serio o que se haga con la esperanza de que se interprete que no tiene un fin serio».

${ }^{102}$ No solamente: cf. Infra, n. 21.

${ }^{103}$ V. G. H. TReitel, op. cit., p. 162 y ss., especialmente, p. 172.

${ }^{104} \mathrm{~V}$. las palabras del juez Blackburn reproducidas en la nota del artículo 2.102 de los Principios del Derecho Europeo de los Contratos.

105 [1892] 2 Q. B. 484. 
a cualquier persona que, pese a utilizar su medicamento contra la gripe, contrajera la enfermedad. Quizás en este asunto la Cour de Cassation pudiera ver hoy en día una operación publicitaria -no muy alejado sin duda de la promesa de un premio de una lotería- y negara ver en este ofrecimiento una intención real de vincularse contractualmente. Sin embargo, fue la calificación contractual la que fue defendida por la Court of Appeal pese a que la propia demandante, Mme. Carlill, no había adquirido directamente el producto del fabricante.

Si los principios Unidroit guardan silencio al respecto ${ }^{106}$, los principios europeos objetivan igualmente el consentimiento ${ }^{107}$, al igual que hace la Convención de Viena de 11 de abril de 1980, que constituye, recordemos, el régimen jurídico francés aplicable a la compraventa internacional de mercaderías ${ }^{108}$.

Ante estas circunstancias, se puede lamentar el silencio que mantiene el Anteproyecto de reforma del derecho de las obligaciones sobre el consentimiento objetivo. Y podemos lamentar que su artículo 1105 ( «La formación del contrato requiere la concurrencia de varias voluntades firmes y concretas de contratar») refleje un subjetivismo persistente. Una elección semejante no carecería de consecuencias: condena al juez francés a recurrir a artificios para calificar las situaciones que tienen toda la apariencia de un contrato, pero en las que subsiste una duda sobre la voluntad de las partes de contratar.

19. Extrapolando este estudio a otro terreno, convendría preguntarse si, en ausencia de toda declaración de las partes contratantes, su silencio debiera ser interpretado como un consentimiento implícito del contrato. Esta pregunta pierde sin embargo interés desde el momento en que las divergencias se difuminan en Derecho comparado. En la mayor parte de los sistemas jurídi-

${ }^{106}$ No obstante, es preciso subrayar que en la interpretación del contrato -no en su formación- es el método objetivo el preconizado: cf. Art. 4.2.

${ }^{107}$ Art. 2:102: «La voluntad de una parte de obligarse por contrato se determinará a partir de sus declaraciones o su conducta, tal y como éstas fueran razonablemente entendidas por la otra parte».

${ }^{108}$ Art. 8: «1) A los efectos de la presente Convención, las declaraciones y otros actos de una parte deberán interpretarse conforme a su intención cuando la otra parte haya conocido o no haya podido ignorar cuál era esa intención.

2) Si el párrafo precedente no fuere aplicable, las declaraciones y otros actos de una parte deberán interpretarse conforme al sentido que les habría dado en igual situación una persona razonable de la misma condición que la otra parte.

3) Para determinar la intención de una parte o el sentido que habría dado una persona razonable deberán tenerse debidamente en cuenta todas las circunstancias pertinentes del caso, en particular las negociaciones, cualesquiera prácticas que las partes hubieran establecido entre ellas, los usos y el comportamiento ulterior de las partes». 
cos, el silencio no equivale a consentimiento ${ }^{109}$. Pero todos admiten excepciones, en concreto cuanto el comportamiento de las partes es revelador de su voluntad, como puede ser el hecho de que la parte a la que se le ofreció el contrato, comience a ejecutar aquello a lo que supuestamente se habría comprometido en el contrato ${ }^{110}$.

Aquí es necesario constatar que el Derecho francés no muestra ninguna singularidad. Al igual que sus ordenamientos vecinos, niega todo valor al consentimiento por el mero hecho del silencio ${ }^{111}$, pero considera que en determinadas circunstancias el comportamiento de las partes es elocuente: es el caso del conductor de un taxi que estaciona su vehículo en una plaza reservada para ello ${ }^{112}$, o del arrendador que al final del arrendamiento no exige al arrendatario el desalojo ${ }^{113}$. El primero hace una oferta tácita, el segundo acepta la oferta tácita de prórroga del contrato permaneciendo en el inmueble alquilado. En realidad, las excepciones son numerosas, como parece apuntar la redacción propuesta de nuevo artículo 1105-6 del Código Civil en el Anteproyecto de reforma del Derecho de las obligaciones: «en la ausencia de disposición legal, acuerdo entre las partes, usos profesionales o de las circunstancias particulares, el silencio no equivale a aceptación».

En definitiva, un juego muy casuístico de principios y excepciones, en el que no será difícil encontrar el consenso entre los juristas europeos. Todos deberían aprobar el artículo 2.204 de los Principios europeos, según el cual el silencio o la inactividad no equivalen a la aceptación, a menos que el comportamiento del destinatario indique conformidad con la oferta ${ }^{114}$. El proyecto Gandolfi establece un artículo específico para las «conductas concluyentes» ${ }^{115}$. En definitiva, todos los sistemas persiguen un mismo fin: alcanzar un equilibrio justo entre el respeto a la voluntad individual y la seguridad jurídica. El respeto a la voluntad de la persona impide considerar que se ha concluido un contrato cuando ni las palabras ni los actos son reveladores del deseo de la parte de obligarse contractualmente. Sin embargo, la seguridad jurídica exige que cada uno pueda confiar en la apariencia de contrato creada por la otra persona ${ }^{116}$.

${ }^{109}$ V. H. Kötz y A. FLeSSNER, European Contract Law, op. cit. p. 27, s. En el mismo sentido, el comentario al artículo 2.204 de los Principios del Derecho Europeo de los contratos, p.131.

${ }^{110}$ V. H. KötZ y A. Flessner, European Contract Law, op. cit. p. 27.

${ }^{111}$ Cass. Civ, 25 mayo 1870, DP. 70.1.341: «En ausencia de cualquier otra circunstancia, en Derecho el silencio de la persona a la que pretendemos obligar no es suficiente para hacer prueba contra él de la existencia de la obligación alegada».

${ }^{112}$ Cass. $1^{\text {ère }}$ civ., 2 diciembre 1969, Bull. n. ${ }^{\circ}$ 381, RTD Civ. 1970, p. 589.

${ }^{113}$ C. civ., art. 1738 .

${ }^{114}$ Este artículo es una declinación del artículo 2.102 anteriormente citado.

115 Código Europeo de los Contratos, art. 24.

${ }^{116} \mathrm{~V}$. Para una aclimatación de este principio tal y como está formulado en el Derecho inglés, H. Muir-WatT, «Reliance et définition du contrat», en Prospectives du droit économique, Dialogues avec Michel Jeantin, Dalloz, 1999, p. 57. 


\section{Incertidumbre sobre el valor contractual del acuerdo}

20. En este punto se abordarán los supuestos en que la existencia del acuerdo está fuera de toda duda pero en los que las partes, según la apariencia, no son conscientes o no han tenido la voluntad de atribuirle un valor contractual. En estos casos, ¿debe el juez partir de la existencia de acuerdo entre las partes y reconocer una acción contractual al demandante?

Esta cuestión quizás sorprenda al jurista francés. Si un acuerdo cumple los requisitos legales de un contrato, el juez está vinculado por él. Sin embargo, la definición proporcionada por el artículo 1101 del Código Civil es muy amplia $^{117}$ y no parece que pueda referirse a todos los acuerdos de voluntad. Incluso no todos aquellos que tienen un valor jurídico merecen la calificación de «contrato». ¿Acaso debe entenderse que dos familiares, dos amigos, dos vecinos... concluyen un contrato por el mero hecho realizar una prestación en beneficio del otro?

La respuesta puede encontrarse en las condiciones de validez (¿o de existencia?) del contrato enumeradas en el artículo 1108 del Código Civil. Desprovisto de un objeto cierto o de causa, el acuerdo no es un contrato. Y es el juez quien está llamado a verificar la determinación del objeto o la existencia de la causa. Aquí están las herramientas que la ley proporciona. Por lo tanto no hay que sorprenderse de las grandes dificultades que en ocasiones encuentra el juez para apreciar el valor contractual de determinados acuerdos. El mejor ejemplo lo podemos encontrar en los servicios de benevolencia. Imaginemos el supuesto en el que una persona consiente en prestar a un familiar o a un amigo un servicio no remunerado y que, en el transcurso de la operación, causa un determinado daño o perjuicio. ¿La responsabilidad del uno o del otro es de naturaleza contractual? No se puede negar que las partes hayan llegado a un acuerdo. Pero, sin lugar a dudas, ninguna de ellas tiene la intención de vincularse contractualmente. En estas condiciones, ¿se puede exigir al transportista que lo es a título gratuito los niveles de seguridad exigibles al transportista a título oneroso? Para evitar estas consecuencias es preciso considerar que la situación no es contractual. En el supuesto en el que se sufriera un daño, sería preciso probar la culpa extracontractual del transportista para obtener la reparación del daño. La Cour de Cassation no ha querido posicionarse entre los intereses en presencia, legítimos pero contradictorios al mismo tiempo. Y, como regla general, considera que se trata de una cuestión de hecho que debe ser resuelta según el poder soberano de apreciación del juez que conoce del fondo del asunto. Serán ellos quienes deban indagar si se ha concluido un «acuerdo de asistencia» entre las par-

${ }^{117}$ Cf. supra, nota 8. 
tes ${ }^{118}$, pudiendo llegar a la conclusión de que no existe relación contractual alguna y que la relación existente entre las partes es una «mera relación de cortesía» ${ }^{19}$. Algún sector doctrinal considera que en estos casos no sería procedente hablar de contrato o de culpa extracontractual, sino de gestión de negocios ajenos ${ }^{120}$. En algunas ocasiones pueden estar en lo cierto ${ }^{121}$.

21. Los jueces ingleses no parecen tener las mismas dificultades puesto que no están sujetos a una definición abstracta de contrato ${ }^{122}$. En principio, consideran que no existe contrato si no hay una intención de las partes de vincularse jurídicamente ${ }^{123}$. Y de esta manera presumen que, en ausencia de esta voluntad, las promesas hechas en un contexto familiar o de relación social (social and family arrangements) no vinculan jurídicamente a su autor ${ }^{124}$. Cabe notar que esta situación no es contractual puesto que ni siquiera es jurídica. Como ya se ha dicho, descartar la calificación contractual no implica necesariamente, en derecho inglés, afirmar la responsabilidad extracontractual ${ }^{125}$.

Dos asuntos ilustran bien la forma de enfocar el problema. El asunto Balfour v Balfour, que enfrentaba a dos cónyuges. El matrimonio Balfour había vivido en Ceilán, lugar donde trabajaba el esposo. La señora Balfour, por problemas de salud, decidió permanecer en Inglaterra, razón por la cual su marido se comprometió a entregarle una renta mensual de treinta libras. Una vez el matrimonio fue disuelto, el Sr. Balfour dejó de pasarle esta cantidad a su mujer. La demanda que interpuso la Sra. Balfour fue desestimada por entender el juez que el acuerdo existente entre ellos no era jurídicamente vinculante (enforceable agreement). Los acuerdos entre esposos no son jurídicamente vinculantes puesto que, salvo circunstancias particulares o disposición en contrario, se presume que el matrimonio no tiene intención de obligarse contractualmente ${ }^{126}$.

118 Cass. $1^{\text {ère }}$ civ., 16 diciembre 1997, Bull. n. ${ }^{\circ}$ 376; D. 1998, Jur. P. 580, nota M. VIALA; Cass. $1^{\text {ère }}$ civ., 17 diciembre 1996, Bull., n. ${ }^{\circ}$ 463; D. 1997, somm. P. 288, obs. PH. DeleBECQUE; RTD, Civ. 1997, p. 431, obs. P. JouRdAIN.

119 Cass. $2^{\text {ème }}$ civ., 26 enero 1994, Rev. crit. et. assur. 1994, comm. N. ${ }^{\circ} 114$; RTD Civ. 1994, p. 864, obs. P. JouRDAIN, JPC G, 1994.I.3809, N. ${ }^{\circ} 1$ obs. G. VINEY.

${ }^{120} \mathrm{R}$. Bout, these precité $\mathrm{n} .^{\circ} 282$, s. y «La convention dite d'assistance», en Mélanges Kayser, 1979, t. I, p. 157 s.

${ }^{121} \mathrm{~V}$. para supuestos de profesionales de la salud que prestan altruistamente sus servicios para una asociación humanitaria y fallece en un accidente de avión fletado por la asociación, Cass. $1^{\text {ère }}$ civ., 2 marzo 2004, Bull. n. ${ }^{\circ} 64$.

${ }^{122}$ A decir verdad, la idea misma de que pueda existir un derecho del contrato, más allá de las reglas aplicables a los contratos (especiales) no ha surgido de manera espontánea y resulta discutida. V. S. HeDleY: op. cit., esp. p. 402 y ss.

${ }^{123}$ Cf. supra, n. $^{\circ} 18$.

124 V. G. H. TReitel, op.cit. p. 164 y ss.

${ }^{125}$ En defecto de un principio general de responsabilidad extracontractual. Cf. Supra, n. ${ }^{\circ} 5$.

${ }^{126}$ Blafour v. Balfour, [1919] 2 KB 571. 
Los hechos fueron diferentes en el asunto Merrit v Merrit ${ }^{127}$. El matrimonio se había ya separado cuando el marido aceptó conceder a su mujer el uso y disfrute del hogar común, mientras que ella se comprometía a pagar el préstamo que habían pedido para financiar la adquisición de la vivienda. Amortizado el préstamo, se entendió que el marido estaba vinculado por la promesa hecha a su mujer ya que al estar separado de ella podía tener la intención de vincularse jurídicamente. Además, es preciso subrayar que en este asunto la esposa había ejecutado su parte del acuerdo y había actuado en consideración al compromiso asumido por su marido. Este acuerdo tenía, por lo tanto, una naturaleza de indudable carácter contractual ${ }^{128}$.

En definitiva, en este tipo de asuntos es la relación de proximidad existente entre las partes la que determina a priori la naturaleza contractual o no -jurídica o no- del acuerdo. Este mismo razonamiento es el seguido en el marco, no de las relaciones familiares, sino sociales: salvo circunstancias particulares, están sujetas a una presunción de «no contractualidad». Así sucede, por ejemplo, en el supuesto en que el propietario de un vehículo acepta llevar al trabajo a un compañero que, por su parte, contribuye al pago del carburante: en el supuesto en que no se prestara el servicio, este último no tendría una acción contractual ${ }^{129}$. Por el contrario, si el transporte tiene lugar, y éste no contribuye al pago de la gasolina, puede ser obligado judicialmente a ello ${ }^{130}$.

Aunque técnicamente, la exclusión de este tipo de acuerdos se justifica por la ausencia de intención contractual, en el fondo subyace la preocupación de limitar el imperio de la ley, que «no debe inmiscuirse en las relaciones de amistad» ${ }^{131}$. Lord Atkin afirma en el asunto Balfour $v$ Balfour que si se consideraran contractuales este tipo de acuerdos sería necesario multiplicar el número de tribunales ingleses. Por lo tanto, es preciso dotarse de los instrumentos jurídicos necesarios para controlar eficazmente la expansión del contrato. Es lo que sucede con el criterio de la intention to create legal relations. Sin embargo, algunos consideran que no es necesario ir tan lejos y que la presunción negativa propuesta en el asunto Balfour $v$ Balfour da carta blanca al juez para establecer la responsabilidad contractual cuando le parezca oportuno ${ }^{132}$.

127 [1970] 2 All ER 760; [1970] 1 WLR 1211; CA.

128 S. HEDLEY, op.cit. p. 406.

${ }^{129}$ Coward v. Motor Insurers' Bureau, [1963] 1 QB 259, [1962] \& All ER 531.

${ }^{130}$ Mc.Goodnan v Motor Insurers' Bureau, [1969] 2 Lloyd's Rep 34 QBD.

${ }^{131}$ A. SerIEAUX, «L'oeuvre prétorienne in vivo: l'exemple de la convention d'assistance», en Mélanges Cabrillac, 1999, p. 299 (nota 7).

${ }^{132}$ V. S. HEDLEY, «Keeping contract in its place...», op. cit. esp, p. 403. 


\section{El acuerdo incompleto}

22. Imaginemos un supuesto en el que no se discuta la existencia de un contrato. Sabemos que este acuerdo está llamado a producir más efectos que los estipulados por las partes. Ahora bien, según su cultura, los juristas no atribuirán el mismo valor -contractual o no- a los efectos que produzca.

En Derecho francés, no hay duda de que son tan contractuales las obligaciones nacidas de la imaginación de las partes como las creadas por la ley o el juez. Por otra parte, la cuestión se confunde en parte con la interpretación «completiva» del contrato. No hay tanta diferencia entre las obligaciones de seguridad o de información y la atribución de determinadas obligaciones a una voluntad hipotética de las partes ${ }^{133}$. De todas maneras tendrá carácter contractual, ya sea una obligación impuesta por la ley o suplementaria de la voluntad de las partes, ya sea considerado por el juez como una consecuencia natural del contrato ${ }^{134}$ o como un efecto deseado por las partes.

El lenguaje jurídico italiano dispone de un bello concepto para denominar este fenómeno: l'integrazione del contratto. Es interesante subrayar que el Codice civile es mucho más explícito en este punto que el Código civil francés. Encontramos una disposición idéntica del artículo 1135 del Código civil: el artículo 1374 del Codice civile ${ }^{135}$. En sede de las obligaciones inherentes a las estipulaciones contractuales, el artículo 1339 del Códice establece que «las cláusulas (...) impuestas por la ley (...) forman parte de pleno derecho del contrato y sustituyen, en su caso, a las estipulaciones contrarias de las partes». El artículo 1340 añade que «los usos y costumbres forman parte del contrato, en defecto de estipulación en sentido contrario de las partes». Siendo parte del contrato, las obligaciones ajenas a la voluntad expresa de las partes son necesariamente de naturaleza contractual.

23. En ciertas situaciones sería demasiado artificial recurrir al contrato para delimitar el litigio surgido entre las partes. A veces es la contrapartida de la extensión considerable del elemento contractual en el Derecho francés. Por ejemplo, el notario cumple una función de servicio público. Sin embargo, no encontramos nada mejor que el contrato para explicar la relación con sus clientes. ¿Significa eso que hay que aplicar la ley del contrato a toda acción de responsabilidad que pudieran éstos ejercitar? La Cour de Cassa-

133 «Quizás haría falta tener el valor de reconocer que la interpretación del contrato, como la de la ley, tiene sus límites, y que existe un cierto grado de oscuridad y contradicción que impide averiguar la común intención de las partes» (CARBOnNIER, Droit civil, t. 4, Les obligations, 22 ème èd. PUF, 2000, n. ${ }^{\circ} 146$.

134 V. C. civ. Art. 1135.

135 «El contrato obliga a las partes no sólo a aquello a lo que se han comprometido, sino también a todas las consecuencias que derivan de la ley o, en su defecto, de la costumbre y la equidad». 
tion ha respondido claramente que no, haciendo incluso de la responsabilidad contractual la excepción: «si las obligaciones del notario, que no hace sino asegurar la eficacia de acto instrumentado por él y que no son la prolongación de su misión de redacción del documento público pertenecen al ámbito de la responsabilidad extracontractual, sería diferente si éste contrajera una obligación contractual con su cliente, por ejemplo, el compromiso de proceder él mismo a la sustitución de la garantía» ${ }^{136}$. Esta afirmación establece claramente que la responsabilidad profesional del notario no supone una violación del contrato, sino un fallo en el cumplimiento de su función legal, con independencia de que sea el contrato el instrumento que le sirve al cliente para dirigirse contra él. Este razonamiento lleva a las mismas consecuencias en supuestos similares en que existe una persona que desarrolla una función legal, como pudiera ser el subastador ${ }^{137}$, el agente judicial ${ }^{138}$ o incluso el centro de reeducación de menores internados por decisión judicial ${ }^{139}$. En estos casos, el criterio de la calificación extracontractual es el origen legal (extracontractual) de la obligación desconocida. Ahora bien, todos los contratos o casi todos contienen obligaciones legales cuya violación está castigada contractualmente. Pero, sin duda, la prestación del notario o del oficial de justicia es esencialmente estatutaria, en el sentido de que el papel de la ley es más importante que el del contrato. No hay que olvidar que el recurso a estos profesionales viene impuesto por la ley, incluso aunque se vista posteriormente de contrato.

24. Algunos sistemas jurídicos llegan a consecuencias más sistemáticas sobre la fuente -convencional o no- de la obligación. Así, por ejemplo, el Derecho inglés tiende a considerar que las obligaciones impuestas a las partes por la ley o por el juez no son contractuales, lo que quizás puede ser un indicio de una influencia mayor que en el Derecho francés de la autonomía de la voluntad. No obstante, por mucho que haya sufrido un retroceso similar al que ha experimentado en el Derecho francés, parece que su influencia ha sido, y sigue siendo, muy grande ${ }^{140}$.

En algunos casos, es toda la situación litigiosa, globalmente considerada, la que escapa a la materia contractual. En el asunto Norweb plc $v$ Dixon $^{141}$, se afirmó que la relación entre una sociedad privatizada de sumi-

136 Cass. 1ère civ. 12 abril 2005, Bull. N. 178; Défrenois 2005, p. 2010, obs. J. L. AUBERT. Las decisiones en materia de responsabilidad extracontractual son muy numerosas.

${ }^{137}$ Cass. 1ère civ. 22 noviembre 1994, n. ${ }^{\circ}$ 92-20917.

138 Cass. 1ère civ. 13 enero 1987, Bull. n. ${ }^{\circ} 12$.

${ }^{139}$ Cass. 2ème civ., 20 enero, Bull, n. ${ }^{\circ}$ 15, D 2000, jur. p. 571, nota M. HuYETTE.

${ }^{140}$ V. P. S. AтIYAн, The Rise and Fall of Freedom of Contract, 1979.

141 [19995] 3 All ER 952, [1995] 1 WLR 636. V. déjà, Read v. Croydon Corporation, [1938] 4 All ER 631. 
nistro de energía eléctrica y un consumidor no era una contractual porque, por un lado, la sociedad soportaba la obligación legal de suministrar al consumidor si se cumplían determinadas condiciones y, por otro, porque la ley fijaba las condiciones (principalmente, las tarifas) bajo las que debía suministrarse la energía eléctrica. Esta intromisión de la ley, tanto en la creación de la relación de derecho como en la determinación de sus consecuencias, es incompatible con una relación de carácter contractual.

En otros supuestos, la situación es contractual a pesar de la existencia de obligaciones no pactadas expresamente por las partes. ¿Cuál es en estos casos la naturaleza de estas obligaciones? La mayor parte de ellas no adquieren jamás carácter contractual. Simplemente, el juez considera que una parte contratante debe soportar una obligación legal (legal duty), cuya violación comporta una responsabilidad extracontractual (in tort). La existencia de un contrato no supone obstáculo alguno puesto que el Derecho inglés no prohíbe la concurrencia de responsabilidades, contractual y extracontractual $^{142}$. En numerosos contratos concluidos por profesionales, principalmente, la incompetencia o la negligencia del contratante es normalmente sancionada in tort $^{143}$.

Sin embargo, junto a estas obligaciones legales, algunas cláusulas no acordadas expresamente por las partes son asociadas a su voluntad implícita (denominadas implied terms) ${ }^{144}$. Las obligaciones que nacen de estas cláusulas son de naturaleza contractual, como contractual es la responsabilidad contraída en el caso de su incumplimiento. A primera vista, la práctica inglesa y la francesa no son tan diferentes en este punto. Pero es preciso distinguir, porque la categoría de implied terms es muy amplia. Podemos encontrarnos con disposiciones impuestas por el Derecho para determinada categoría de contratos, bajo una forma legal (terms implied by statute) o jurisprudencial: la voluntad implícita de las partes en este punto no tiene gran importancia, incluso si los implied terms pueden ser excluidos por medio de disposición expresa en contrario de las partes ${ }^{145}$. Otros términos vienen implícitos por la costumbre o los usos: éstos no precisan de la intención presunta de las partes, pero, sin embargo, tampoco la pueden contradecir $^{146}$. Finalmente están los terms detectados por el juez en cada contrato

${ }^{142}$ Cf. infra n. $^{\circ} 29$.

${ }^{143} V$. los ejemplos propuestos por E. A. JAFFEY, «Contract in tort's clothing», Legal Studies, 1985 , p. 77.

${ }^{144}$ V. G. H. TReITEL, op. cit., p. 201 y ss.

${ }^{145}$ Op. cit., pp. 206-211. El leading case es Liverpool City v. Irwin ([1977] A.C. 239): Debido al estado general de deterioro de las viviendas de un barrio de Liverpool, una pareja de arrendatarios apeló a la responsabilidad contractual del ayuntamiento: la Cámara de los Lores les dio la razón, entendiendo que un contrato de arrendamiento contiene unos implied terms según los cuales el arrendador debe tomar las medidas razonables que sean necesarias para mantener los equipamientos del inmueble en buen estado de uso y conservación.

${ }^{146}$ Op. cit. p. 213. 
individual. Éstos tampoco pueden, mucho menos que en el Derecho francés $^{147}$, estar asociados sistemáticamente a la voluntad real de las partes ${ }^{148}$. Como lo avanzaba Lord Wilberforce en el asunto Nacional Carriers Ltd. $v$ panalpina (Northern) Ltd. ${ }^{149}$, «abandonando una interpretación estricta de la teoría de la autonomía de la voluntad, el derecho del contrato permite a los jueces descubrir -mejor, imponer- las soluciones justas que hubieran acordado hombres razonables en una situación similar a la de los contratantes». No se podría definir mejor la construcción jurisprudencial del contrato. Sin embargo, si se analiza con detenimiento, las aproximaciones son diferentes. El juez francés se preocupa más de moralizar el contrato y de facilitar a la víctima el camino hacia la indemnización. Poco le preocupa la economía del contrato. Sin embargo, aunque es cierto que el juez inglés no es insensible a la moralidad contractual, tiende a reconocer pleno efecto al contrato y a las estipulaciones de las partes. Uno de los criterios desarrollados para identificar en el contrato los implied terms es precisamente el de la eficacia comercial, la business efficacy ${ }^{150}$. Este criterio ha sido establecido por la sentencia The Moorcock de 1989151. Por medio de un contrato concluido entre un armador y el propietario de un embarcadero situado en el río Támesis, se acordaba la utilización del embarcadero para la descarga del barco. En el proceso de descarga, y debido a la fuerza de la marea, el barco encalló y sufrió una serie de daños. La Court of Appeal entendió que el propietario del navío había implícitamente contratado la seguridad del lugar, incluso con la marea baja. Ampliamente utilizado desde entonces, el criterio de la business efficacy permite completar el contrato con el grado de eficacia que las partes hayan podido razonablemente desear ${ }^{152}$. No es necesario considerar una disposición como razonable, ni entender que mejora el contenido del contrato. Es preciso asegurar que las partes contratantes hubieran prestado su consentimiento si hubieran reflexionado sobre ella ${ }^{153}$.

Se trata de determinar lo que debe ser considerado como contractual por adhesión al contrato. Según el criterio que se mantenga, será contractual aquello que equilibra o moraliza el contrato, o aquello que contribuye a su eficacia. El Derecho francés comparte el primer enfoque, mientras que el Derecho inglés se aproxima más al segundo.

${ }^{147}$ Cf. Supra, n. ${ }^{\circ} 22$

${ }^{148}$ V. principalmente A. PHANG, «Implied Terms in English Law - Some recent developments», The Journal of Business Law, 1993, p. 242.

${ }^{149}$ [1981 AC 675-696].

150 V. A. PHANG, «Implied Terms, business efficacy and the officious Bystander - A modern history», The Journal of Business Law, 1998, p.1.

${ }^{151}$ [1889] 14 PD 64.

${ }^{152}$ V. G. H. TReITEL, op. cit., p. 202.

${ }^{153}$ Op. cit. p. 203. Se utiliza un segundo criterio: el del officious bystander, o cláusula que el tercero que hubiera asesorado a los contratantes habría recomendado incluir y que las partes hubieran consentido (Shirlaw v. Southern Foundries 1926 Ltd. [1939] 2 K.B. 206). 
Los Principios Europeos se sitúan en la confluencia de ambas corrientes. El artículo 6.102, titulado «Obligaciones implícitas» prevé que «además de las obligaciones expresas, un contrato puede contener obligaciones implícitas que derivan de: a) la intención de las partes; b) la naturaleza y finalidad del contrato; c) la buena fe». Es decir, la búsqueda de la voluntad real pero no manifiesta, la promoción de la eficacia contractual y la preocupación de moralizar el contrato. El juez francés aplicará con más facilidad los apartados a y c, mientras que el juez inglés los apartados a y $\mathrm{b}^{154}$. Más concretamente, el proyecto Gandolfi distingue entre cláusulas implícitas impuestas por la ley, aquellas que dimanan de la buena fe o de la voluntad tácita de las partes y, finalmente, aquellas «que son necesarias para que puedan producirse los efectos pretendidos por las partes» ${ }^{155}$. La business efficacy no está lejos.

\section{EL CONTRATO COMO FUENTE DE OBLIGACIONES}

25. Cambiemos de ángulo: examinemos a continuación el contrato a través de su función. Se plantean, pues, varias cuestiones. ¿Acaso no existe el contrato a menos que haga nacer obligaciones? Y, en caso contrario, ¿el contenido no obligacional del contrato es en sí mismo contractual? ¿Es posible incorporar al contrato toda obligación, sea cual sea su objeto? ¿Supone el contrato la existencia de obligaciones recíprocas?

\section{A. Contenido no obligacional del contrato}

26. Hemos apuntado como introducción que el contrato no interesaba al derecho salvo en la medida en que era generador de obligaciones. ¿Es exacta esta afirmación? Se puede dudar si es cierto que la utilidad del contrato no se limita a las obligaciones que conlleva. La doctrina en efecto ha puesto en evidencia la existencia de un efecto no obligacional del contrato ${ }^{156}$. Y la misma idea se ha aparecido en textos recientes, como el proyecto Gandolfi de Código europeo de los contratos ${ }^{157}$. Algunos contratos tienen incluso un

${ }^{154}$ En el mismo sentido, el comentario a este artículo por D. BosCo en Regards croisées sur les principes du droit européen du contrat et sur le droit français, PUAM, 2003, p. 325.

${ }^{155}$ Art. 32.

${ }^{156}$ V. en Francia, P. ANCEL, «Force obligatoire et contenu obligationnel du contrat», RTD Civ. 1999, p. 771.

${ }^{157}$ V. la definición del contrato propuesta en el artículo 1: «el contrato es el acuerdo de dos o más partes destinado a crear, regular, modificar o extinguir una relación jurídica, de la que pueden derivarse obligaciones y otros efectos, incluso a cargo de una sola parte» (cursiva añadida). Nada comparable en importancia con el anteproyecto de reforma del derecho de obligaciones, que se queda en una definición puramente obligacional: «El contrato es un acuerdo por el cual una o varias personas se obligan con otra u otras a realizar una prestación» (Art. 1102). 
efecto principalmente no obligacional, como los que transfieren derechos reales o instituyen uniones pseudomatrimoniales. Pero hay que reconocer que esos contratos plantean dificultades considerables en derecho comparado.

Por ejemplo, Francia ha elegido hacer del Pacte civil de solidarité (PACS) un contrato ${ }^{158}$, pero los países escandinavos o los Países Bajos tienen una concepción más institucional de las parejas de hecho registradas, lo que les acerca claramente al matrimonio. Además, hay que tener en cuenta que en estos países no reconocen ni el uno ni el otro estas formas de unión y regulan en consecuencia las cuestiones que plantean las parejas de hecho por aplicación del derecho común. Éste es el caso del derecho italiano, que no concede a los componentes de la pareja de hecho un estatus jurídico específico ${ }^{159}$. Salvo alguna excepción, sus derechos y deberes se rigen por el derecho común -derecho del enriquecimiento sin causa, fundamentalmente-. Se admite por lo demás que los componentes de la pareja de hecho pueden concluir válidamente acuerdos que regulen sus relaciones patrimoniales. De ello se deriva que cierto número de situaciones serán contractuales, como en Francia, pero por razones diferentes.

Los contratos de transmisión de derechos reales no suscitan menos interrogantes. Primero porque, en derecho francés incluso, no existe acuerdo sobre la naturaleza de la transferencia de la propiedad: ¿efecto obligatorio del contrato u objeto de una obligación del vendedor ${ }^{160}$ ? Seguidamente, porque las divergencias más profundas dividen los sistemas jurídicos nacionales. Para convencerse de ello basta con oponer el acuerdo de voluntades del derecho francés ${ }^{161}$ y una concepción alemana muy formal, según la cual la transferencia de la propiedad no se deriva de un contrato de venta en sí mismo, sino de un acuerdo específico posterior a la venta y sometido a publicidad (registro para los inmuebles, desposesión para los muebles). La venta, por su parte, tiene un efecto puramente obligacional, mientras que el efecto real se deriva de un segundo acto, el contrato real ${ }^{162}$. La línea divisoria entre el contrato y lo que le es ajeno varía pues de un país a otro. Esta divergencia, que no se limita a la comparación franco-alemana, explica que en tanto que se ha armonizado el derecho material de la venta internacional de mercancías, se ha renunciado a regular la transferencia de la propiedad ${ }^{163}$. Y apenas se ha intentado unificar sobre este punto las reglas del conflicto de leyes:

${ }^{158}$ C. civ., art. 515-1. Por la misma solución ha optado la «cohabitación legal» belga: v. C. civ., art. 1475 y ss.

${ }^{159}$ V. sobre lo que el derecho italiano denomina la famiglia di fatto, L. BALESTRA, «Les concubinages en Italie: aspectos jurídicos», en Mélanges Rubellin-Devichi, p. 405.

${ }^{160}$ V. P. ANCEL, op. cit., n. ${ }^{\circ} 17$ y s.

161 V. C. Civ., art. 1583.

${ }^{162}$ V. F. FerRAND, Droit privé allemand, Dalloz, 1997, n. ${ }^{\circ} 612 \mathrm{~s}$.

${ }^{163}$ El artículo 4(d) de la Convención de Viena excluye del campo de aplicación de este texto «los efectos que el contrato pueda tener sobre la propiedad de las mercancías vendidas». 
los convenios de La Haya de 1955 y de 1986 excluyen ambos de su campo de aplicación la transferencia de propiedad ${ }^{164}$. En cuanto al Convenio del 5 de abril de 1958, que precisamente tiene por objeto determinar la ley aplicable a la transferencia de la propiedad de los bienes vendidos, jamás ha entrado en vigor por falta de ratificaciones ${ }^{165}$.

Habría que proseguir esta investigación para verificar si los efectos no obligacionales del contrato ocasionan más disparidades en derecho comparado que sus efectos obligacionales. Si, como suponemos, esta hipótesis se verifica, ¿no será porque al final resulta artificial recurrir al contrato para hacer que produzca un efecto puramente legal ${ }^{166}$ ? Lo que es cierto es que el contrato que ya no es estrictamente obligacional tiende naturalmente a invadir otras ramas del derecho ${ }^{167}$. Se seguirá diciendo que esta o aquella institución es contractual, pero a menudo será imposible regular sus efectos por la sola aplicación del derecho de los contratos. Se puede incluso dudar que el derecho contractual supranacional sea de alguna utilidad para estos contratos. Los Principios europeos, de inspiración ${ }^{168}$ y práctica ${ }^{169}$ marcadamente mercantilista, ¿pueden ser de utilidad para su aplicación al contrato de PACS o a cualquier otra pareja de hecho registrada? Sin duda, la respuesta es no. El proyecto von Bar, por su parte, descarta expresamente estas materias ${ }^{170}$. $\mathrm{Y}$ es igualmente porque estas situaciones no corresponden al arquetipo del contrato que están excluidas del ámbito de aplicación de instrumentos como la Convención de Roma de 19 de junio de 1980 sobre la ley aplicable a las obligaciones contractuales o el Reglamento de Bruselas de 22 de diciembre de 2000 sobre la competencia judicial, el reconocimiento y la ejecución de decisiones en materia civil y mercantil ${ }^{171}$.

${ }^{164}$ Art. 5(3) de la convención de 1955, art. (c) de la convención de 1986.

${ }^{165}$ La única ratificación, la de Italia, data de 1961. V. sobre estas cuestiones V. HeUZE, La venta internacional de mercancías, LGDJ, 2000, especialmente $\mathrm{n}^{\circ} 55 \mathrm{y} \mathrm{ss.}$

${ }^{166} \mathrm{Se}$ ha visto supra (n. ${ }^{\circ} 23$ ) que los efectos puramente legales de ciertos contratos, como ciertas responsabilidades profesionales, no estaban sometidas al derecho de los contratos y que el derecho inglés no considera incluso como contractual un acuerdo de suministro de electricidad en condiciones fijadas por la ley (n. $\left.{ }^{\circ} 24\right)$.

${ }^{167}$ F. FERRAND explica mediante la correcta distinción entre el derecho de las obligaciones y el derecho de los bienes la distinción alemana entre contrato obligacional y contrato real (op. cit., n. ${ }^{\circ} 613$ ).

${ }^{168}$ V. la introducción a los Principios.

${ }^{169} \mathrm{~V}$. los ejemplos propuestos en los comentarios de cada artículo.

${ }^{170}$ Art. 1.101.

${ }^{171}$ V. en este sentido V. Heuze, «La notion de contrat en droit international privé», op. cit., p. 320. 


\section{B. Obligaciones no contractuales en cuanto a su objeto}

27. Si consideramos ahora los únicos efectos obligaciones del contrato, conviene preguntarse si son todos de esencia contractual. Algunos sistemas califican contractualmente obligaciones que, en otros lugares, tienen distinta naturaleza. Tomaremos como ejemplo las obligaciones que tienen por objeto la integridad del cocontratante o de sus bienes.

Estas obligaciones tienen una «contractualidad» dudosa, desde dos puntos de vista. Primero, porque son en general impuestas por el juez o la ley a la voluntad de las partes -es el caso de la obligación de seguridad del derecho francés-. No volveremos sobre este punto, ya expuesto ${ }^{172}$. La otra razón de dudar del carácter contractual de estas obligaciones tiene que ver con su objeto.

28. Es bastante fácil trazar una línea divisoria teórica entre responsabilidad extracontractual y responsabilidad contractual. La primera tendría por objeto la reparación de un agravio no atendido de la situación de la víctima. La segunda haría referencia a compensar la ausencia del beneficio que debía reportar el cumplimiento del contrato. El contrato es un instrumento de previsión, la responsabilidad contractual es la protección que la ley otorga a esta previsión ${ }^{173}$. Al contrario, la responsabilidad extracontractual es la protección que la ley acuerda a aquel que padece un daño imprevisto. Partiendo de la responsabilidad, podemos remontarnos a la obligación: la obligación contractual tiene por objeto el beneficio prometido al otro; la obligación extracontractual siempre es negativa, pues prohibe a su deudor perjudicar al otro.

Muy presente en algunos derechos extranjeros y acogida en Francia por un aparte de la doctrina ${ }^{174}$, esta división es casi desconocida en el Derecho positivo francés. Muy raras son las decisiones que se refieren a ella expresamente; y las que lo hacen no implican siempre su aceptación ${ }^{175}$. Sobre todo, cada cual dice que el contrato es hoy habitualmente empleado para acudir en

${ }^{172}$ Cf. supra, . $^{\circ} 22$ y ss.

${ }^{173}$ Lo que expresa el artículo 1150 C. Civ.: «el deudor sólo estará obligado al pago de daños e intereses previstos o que hubieran podido ser previstos en el momento del contrato cuando en el incumplimiento de la obligación no existiera dolo por su parte».

${ }^{174}$ V. CARBOnNIER, op. cit., n. ${ }^{\circ}$ 295: «lo que se denomina responsabilidad contractual debería ser concebido como algo muy limitado: la obligación de procurar al acreedor el equivalente del interés (pecuniario) que esperaba del contrato; es el resultado de hacer entrar allá adentro el dolor y la muerte; la tragedia es imputable a los artículos 1382 y siguientes».

${ }^{175}$ V. para una fórmula extraña Nancy, 12 sept. 1986, Juris-data n. $^{\circ}$ 1986-046903: «esta ausencia, si bien consiste en la violación de una obligación contractual, compromete la responsabilidad extracontractual de la sociedad SOPALOR, dado que el daño causado por la negligencia de la antedicha sociedad e invocado por el Sr. BRIERE es ajeno al objeto del contrato». 
ayuda de las víctimas de daños no propiamente contractuales. La obligación contractual de seguridad, especialmente cuando ésta es de resultado, es el instrumento privilegiado de esta opción. Las razones son conocidas: rigidez - probatoria, fundamentalmente- de la responsabilidad extracontractual; imposibilidad de recurrir a ella cuando las partes del litigio están obligadas por un contrato, en virtud del principio de prohibición del concurso de responsabilidades. A decir verdad, tratándose de esto último, no se sabe bien si es la causa o la consecuencia de la expansión del contrato: ¿se inventa un incumplimiento contractual porque está prohibido reparar por la vía extracontractual el daño constatado, o bien se mantiene la prohibición del concurso porque, de todas formas, la responsabilidad hipertrofiada tiene respuesta para todo? Lo que sí es cierto es que los dos fenómenos están íntimamente relacionados. La última década ha sido sin duda la época dorada de la obligación contractual de seguridad; también es la época en la que la Cour de cassation francesa ha dictado sus decisiones más contundentes en materia de prohibición del concurso ${ }^{176}$.

29. La mayoría de los sistemas jurídicos extranjeros autorizan al contratante víctima a optar por uno u otro régimen de responsabilidad ${ }^{177}$. En consecuencia, el daño corporal o a los bienes es, en este caso, naturalmente reparado por la responsabilidad extracontractual, sin que sea necesario distender el contrato.

Dado que no conocía el principio general de responsabilidad extracontractual sino una multiplicidad de torts, era normal que el derecho inglés permitiese su aplicación cada vez que se dieran las condiciones, ya fuese entre contratantes. La especialidad de la materia contractual, a veces invocada en virtud de la prohibición del concurso en derecho francés (specialia generalibus derogant), no es en Common Law un argumento definitivo. Pero esto

${ }^{176}$ Mientras que la fórmula clásica («los artículos 1382 y siguientes no son de aplicación cuando se trate de una falta cometida en la ejecución de una obligación resultante de un contrato»: Req 21 enero 1890, DP 1891, I, 380) obliga al juez a constatar el incumplimiento contractual antes de rechazar la responsabilidad extracontractual, la Cour de cassation ha venido a admitir en los años noventa que la sola existencia de un contrato entre las partes era exclusivo de toda acción delictual. La responsabilidad extracontractual es, en efecto, «ajena a las relaciones de las partes contratantes» (Cass. $2^{\text {ème }}$ civ., 26 mayo 1992, Bull. N. ${ }^{\text {o }}$ 154; Resp. civ. et assur., oct. 1992, n. ${ }^{\circ} 33$, obs. (muy críticas) Ch. LAPOYADE DesChAMPS; JCP G 1992.I.3625, obs. G. VINEY). V. en el mismo sentido Cass. $3^{\mathrm{ème}}$ civ., 9 oct. 1991, Bull. N2 234, RTD Civ 1992 p. 107, obs. P. JourdaIN; Cass. $3^{\text {ème }}$ civ., 10 nov. 1998, Bull. N.o 211 , D. 1999, som. p. 260, obs. P. Jourdain.

${ }^{177}$ Una excepción notable es el caso de Québec, que incluso ha codificado la regla de no acumulación de responsabilidades (C. civ., art. 1458: en caso de incumplimiento de una obligación contractual, ni el deudor ni el acreedor pueden «sustraerse a la aplicación de las reglas del régimen contractual de responsabilidad para optar a favor de las reglas que les fuesen más favorables»). 
no es todo: el derecho inglés efectúa claramente la distinción entre los ámbitos de aplicación respectivos de los dos regímenes de responsabilidad. Al contrato, la producción; a la responsabilidad extracontractual, la protección del individuo y de sus bienes ${ }^{178}$. La división es tan clara, que la responsabilidad in tort no permite en principio reparar un daño puramente económico (pure economic loss), es decir, sin relación con el daño corporal o la degradación de objetos materiales ${ }^{179}$. De forma que la indemnización de este daño depende, en principio, de la responsabilidad contractual. El derecho de torts se aplica a los actos que agravan la situación del otro, no a aquellos que no lo mejoran ${ }^{180}$. Si, no obstante, se da la circunstancia de que el contrato contiene una obligación de respetar la integridad física del acreedor o de sus bienes, esta circunstancia no debe impedir a la víctima de un daño personal o a sus bienes de buscar la reparación in tort. Y los tribunales ingleses han admitido desde muy pronto el concurso de responsabilidades en esta hipótesis ${ }^{181}$. Ha sido más difícil y más largo admitirla en otros casos, como allí donde el daño es puramente económico. En 1994, el caso Henderson v Merret Syndicates Ltd. ${ }^{182}$ dio a la Cámara de los Lores la ocasión de afirmar que «en el contexto actual, el Common Law no es hostil al concurso de responsabilidades, y no existe fundamento válido para una regla que impida de manera automática al demandante ejercer alternativamente un recurso extracontractual o contractual». La sentencia es interesante porque, una vez más, pone por delante la fuente específica de la obligación extracontractual: «si se entiende que la obligación in tort es impuesta por la ley y que la obligación contractual resulta de la voluntad de las partes, se puede admitir que el demandante esté autorizado a beneficiarse del recurso que le sea más favorable».

Por su parte, el derecho italiano de las obligaciones está estructurado a la imagen del francés ${ }^{183}$. Pero esto no le ha impedido autorizar el concurso (concorso) cuando el comportamiento dañoso viole no solamente el contrato, sino también el principio general de neminem laedere ${ }^{184}$. Y el recurso a la responsabilidad extracontractual es frecuente para la reparación de los daños

\footnotetext{
${ }^{178}$ La distinción es de T. WEIR, International Encyclopaedia of Comparative Law, vol. XI, ch. 12, «Complex Liabilities».

${ }^{179}$ V. especialmente J. H. Herbots, «Le duty of care et le dommage purement financier en droit comparé», RRJ 1985, p. 267. V. también, examinando el pure economic loss a propósito de la distinción entre los dos ámbitos de responsabilidad, B. S. MARKESINIS, «An Expanding Tort Law - The Price of a Rigid Contract Law», Tbe Law Quarterly Review, 1987, p. 354.

180 A. E. JAFFEY, «Contract in tort's clothing», op. cit., p. 77.

${ }^{181}$ V. A. BuRrows, «Solving the Problem of Concurrent Liability», in Understanding the Law of Obligations, Hart Publishing, 1998, p. 16.

182 [1994] 3 All E.R. 506, [1995] 2 AC 145.

${ }^{183}$ Cf. supra $\mathrm{n}^{\circ}{ }^{\circ}$.

${ }^{184}$ Cass. 22 sept. 1983, n. ${ }^{\circ}$ 5368, Foro italiano, Massimario, 1983.1180.
} 
causados a las personas o a los bienes en el cumplimiento de un contrato de transporte, del daño médico o incluso del daño causado por la utilización de productos defectuosos ${ }^{185}$. A diferencia del derecho inglés, el derecho italiano no ha excluido formalmente la indemnización extracontractual del daño puramente económico, pero la jurisprudencia parece haberse esforzado, de paso, por conservar un ámbito de intervención propio para cada régimen de responsabilidad ${ }^{186}$. Más recientemente, no se ha sabido resistir a la tentación de contractualizar la reparación de los daños personales ${ }^{187}$, sin que la prohibición del concorso sea, sin embargo, puesta en duda ${ }^{188}$.

30. Es comprensible que ni los principios Unidroit ni los Principios europeos aborden la cuestión del concurso de responsabilidades, en la medida en que tanto los unos como los otros tienen un ámbito de aplicación limitado al contrato. Señalaremos de todas formas que el artículo 9.501 de los Principios europeos contempla la reparación contractual del perjuicio no pecuniario; los comentarios precisan que el perjuicio reparable puede consistir en un daño moral -sufrimiento, dolor, molestia, trastornos psíquicos- resultantes del incumplimiento de la obligación. Según la interpretación que se haga, este texto permitirá pues aplicar la responsabilidad contractual a daños no específicamente contractuales, como los daños a la persona o a los bienes. Por el contrario, el artículo 9.502 nos parece que efectúa una mejor distinción entre el contrato y el delito. Dicho artículo establece que «en general, el cálculo de la indemnización de daños y perjuicios se hará de forma que se coloque al perjudicado en una posición lo más próxima posible a la que hubiera disfrutado de haberse ejecutado correctamente el contrato». En efecto, la norma se autolimita («en general»); por añadidura se puede estimar que si el contrato hubiera sido debidamente ejecutado, el acreedor y sus bienes habrían resultado indemnes y que es esta «posición» (de indemnidad) la que prevé el artículo 9.502. Pero el comentario del artículo no permite esta lectura. Precisa en efecto que «el acreedor tiene derecho a obtener una compensación correspondiente al valor de lo que hubiera podido obtener del cumplimiento del contrato» ${ }^{189}$. Es decir, que el contrato se configura ante todo como un instrumento de producción y no de protección ${ }^{190}$.

${ }^{185}$ V. F. GIARDINA, «Responsabilità contrattuale ed extracontrattuale: una distinzione attuale?», Rivista critica di diritto privato 1987, p. 79; P. G. MONATERI, Cumulo di responsabilità contrattuale ed extracontrattuale - analisi comparata di un problema, CEDAM, 1989.

${ }^{186}$ V. F. GIARDINA, op. cit., pp. 80-82.

${ }^{187}$ Op. cit., pp. 163-164.

188 V. p. ej. Cass. civ. sez. III, 19 janv. 1996, n. 418.

${ }^{189}$ Comm. I (cursiva añadida).

${ }^{190}$ Afirmando que la indemnización de daños y perjuicios del artículo 9.502 «no pretende la compensación del perjuicio de inejecución sino la satisfacción del acreedor», véase el comentario del artículo que realiza V. PERRUCHOt-TRIBOULET, en Regards croisés sur les principes du droit européen du contrat et sur le droit français, op. cit., p. 515. 
Por lo demás, los textos europeos no parecen favorables a una contractualización de la reparación del daño extracontractual. El mejor ejemplo de esto es la responsabilidad derivada de productos defectuosos, resultante de la directiva de 25 de julio de 1985. Esta responsabilidad tiene precisamente por objeto la reparación de daños causados a la persona o a los bienes ${ }^{191}$. Ahora bien, no es, en teoría, ni contractual ni extracontractual y los recursos contractuales o extracontractuales de los que dispone la víctima no le están veda$\operatorname{dos}^{192}$. No hay que ver en esto necesariamente una opción, sino quizá simplemente el rechazo de tomar una posición entre tradiciones jurídicas divergentes. Pero lo que sí es cierto es que este nuevo régimen de responsabilidad, transformado en derecho interno de los países miembros, opera una descontractualización de los daños que cubre.

La principal disonancia se encuentra en el proyecto Gandolfi, que expresamente hace del contrato un instrumento de protección de las partes. El artículo 99, precisamente titulado «Incumplimiento del deber de dejar indemne al acreedor», plantea en efecto que, «en el cumplimiento de la prestación debida, el deudor debe adoptar todas las medidas necesarias para no producir daños a la persona del acreedor, a sus auxiliares y a sus bienes; en caso de infracción de este deber, la obligación debida se considera incumplida si el daño se produce durante o a causa del cumplimiento, y representa una causa directa e inmediata del mismo. En otro caso, el deudor queda sujeto a la responsabilidad aquiliana». La violación de un deber de dejar indemne al acreedor está pues unida al incumplimiento propiamente dicho, con el cual no parece confundirse. De todas formas, la contractualización de la responsabilidad está limitada por la exigencia de un vínculo inmediato y directo entre la una y la otra. En su ausencia, la responsabilidad extracontractual retoma sus derechos. He aquí pues un freno a la expansión contractual que sin lugar a dudas será explotada de distinta forma por cada juez nacional según su propia cultura.

\section{Obligaciones sin contrapartida}

31. ¿Puede haber contrato allí donde no hay reciprocidad? Esta cuestión no es la de la admisibilidad del contrato unilateral, aquél sólo obliga a una parte ${ }^{193}$, sino la del contrato a título gratuito, por el cual una parte se empo-

${ }^{191}$ C. civ., art. 1386-2.

192 Cf. supra, n. ${ }^{\circ} 15$ y nota 77.

${ }^{193}$ C. civ., art. 1103. En la medida en que aquel que se obliga en solitario recibe no obstante una ventaja (por ejemplo, la entrega de fondos en el préstamo a interés), generalmente no se discute que la calificación contractual sea la apropiada. Tal operación cumple satisfactoriamente el intercambio económico (bargain) apreciado en derecho inglés, si bien es discutible en el sentido del derecho francés. 
brece sin contrapartida ${ }^{194}$. Una donación, un depósito o un mandato no remunerado, ¿son contratos?

Para el derecho francés, no hay ninguna incompatibilidad de principio entre gratuidad y contrato. El Código civil presume incluso la gratuidad de los contratos como el depósito ${ }^{195}$ o el mandato ${ }^{196}$. Pero bien se sabe que en la práctica, estos contratos son cada vez menos gratuitos. También se sabe que la gratuidad del mandato, dado que se acompaña de la facultad para el mandante de revocar el mandato cuando le parezca oportuno ${ }^{197}$, ha conducido a la jurisprudencia a inventar la noción de «mandato de interés común», para los casos en los que el mandato aprovecha en realidad las dos partes. Allí donde el Código civil había desechado el derecho común del contrato, la Cour de Cassation lo ha reintroducido. Quizá sea porque el mandato no remunerado no es un auténtico contrato, a pesar de la calificación mantenida por el Código. No llega a serlo sino cuando reaparece el interés común, al menos desde que las dos partes tienen interés en el cumplimiento del acuerdo. En definitiva, sólo hay realmente contrato cuando el acuerdo de voluntades da lugar a un intercambio entre las partes, cuando cada una de ellas consiente en un empobrecimiento o en un sacrificio en beneficio de la otra.

Esta concepción del contrato no es totalmente ajena al derecho francés. Encuentra su expresión en la teoría de la causa, conocida igualmente por cierto número de derechos europeos ${ }^{198}$. Si la causa no es en absoluto un instrumento para lograr el equilibrio contractual ${ }^{199}$, al menos permite asegurar que todo contrato presenta un interés para cada una de las dos partes, lo que es, en todo caso, un contrato. Y todavía esto último no es del todo cierto salvo en el caso de la causa objetiva -no las motivaciones personales de las partes, sino la ventaja objetiva que se espera del contrato- aplicado a los contratos sinalagmáticos. En esta hipótesis, en efecto, la causa permite asegurarse de que la obligación de cada uno tiene como contrapartida la obligación de su cocontratante. El juez anulará todo contrato que no presente ningún in-

\footnotetext{
194 C. civ., art. 1105.

195 C. civ., art. 1917.

196 C. civ., art. 1986.

${ }^{197}$ C. civ., art. 2004.
}

${ }^{198}$ V. los arts. 1325 y 1418 del Codice civile italiano, 1108 y 1131 del Code civil belga, 1261 y 1275 del Código Civil español. Este último propone además una definición de la causa en el artículo 1274. Por el contrario, el BGB alemán no hace de la causa una condición de la existencia del contrato en cuanto tal. La causa -subjetiva- no interviene sino para asegurar que la concordancia de los consentimientos o para sancionar el acuerdo ilícito o inmoral. V. M. PEDAMON, op. cit., n. ${ }^{\circ} 92$.

${ }^{199}$ V. no obstante los propósitos optimistas de D. MAZEAUD, «La matière du contrat», en Les concepts contractuels français à l'heure des Principes du droit européen des contrats, op. cit., p. 81. 
terés para una parte, bien porque la contrapartida sea inexistente, bien porque sea inútil ${ }^{200}$. Por el contrario, tratándose de contratos concluidos a título gratuito, la causa objetiva ya no es de ninguna utilidad. No existe contrapartida objetiva, por ejemplo, en el empobrecimiento del donante. Sin embargo, este empobrecimiento ha de producirse, pero, si no acontece, se aplicarán las reglas del enriquecimiento sin causa. Es por esto por lo que se ha inventado la intención liberal, sustitutiva de la causa. En ausencia de intención liberal, o cuando ésta es falsa, la liberalidad puede ser anulada. Los jueces han determinado, por ejemplo, la nulidad de una donación hecha por un marido a su mujer como consecuencia de que ésta, poco después, había abandonado el domicilio conyugal y había solicitado el divorcio, y ello porque, en este caso, el vínculo afectivo que había estado en el origen de la intención liberal del donante era indisociable de la unión conyugal que existía con la donataria ${ }^{201}$. Estas soluciones son retomadas en el anteproyecto de reforma del derecho de obligaciones $^{202}$, fiel a la teoría de la causa a pesar de las críticas de las que es objeto ${ }^{203}$.

En definitiva, lo que separa aquí lo contractual de lo extracontractual ya no es la economía del intercambio, sino la intención contractual de las partes. No ha habido nunca contrato (éste es el sentido de la retroactividad de la nulidad) porque la intención del donante, equivocada, nunca ha tenido valor contractual. Pero quizá porque esta intención no constituye un criterio suficientemente discriminatorio, la donación debe además constatarse por acto auténtico, bajo pena de nulidad ${ }^{204}$. Volveremos a encontrar una aplicación similar del formalismo en derecho inglés ${ }^{205}$.

32. La aprehensión francesa al contrato de beneficencia no está exenta de reproches. Hace depender la existencia del contrato de acontecimientos posteriores a su conclusión. En el caso de la donación entre esposos seguida de un divorcio, la intención contractual no es apreciada el día del acto, sino a la luz de la demanda de divorcio efectuada ulteriormente. Se presume que

\footnotetext{
${ }^{200}$ V. para la anulación de un contrato de revelación de sucesión, porque la intervención del genealogista no era necesaria para esta revelación, Cass. $1^{\text {ère }}$ civ., 13 avr. 1953, JCP. 53.II.7761.

${ }^{201}$ Cass. $1^{\text {ère }}$ civ., 14 mai 1985, RTD Civ. 1986, p. 397, obs. J. PATARIN. Igualmente, una persona que lega sus bienes a los pobres creyendo sin razón que no hay más herederos puede invocar la ausencia de la causa: París, 9 févr. 1867, S. 1867.2.129.

202 Art. 1125-4: «No hay donación ni testamento en ausencia de intención liberal. Las liberalidades están desprovistas de causa real en ausencia de motivo sin el cual su autor no habría dispuesto».

${ }^{203}$ V. especialmente B. FAVARQUE-COSSON, «La réforme du droit français des contrats: perspective comparative», RDC 2006, p. 147.

${ }^{204}$ C. civ., art. 931.

${ }^{205}$ Infra, n. ${ }^{\circ} 32$.
} 
la intención de divorciarse del donatario sería desconocida para el donante el día del acto, de manera que en esta fecha la intención liberal existía de hecho... y no habría sido nunca contrariada si el cónyuge hubiera renunciado a divorciarse. Quizá sería mejor dotarse de instrumentos más rigurosos para apreciar la existencia del contrato desde su conclusión. En este caso, el derecho inglés parece estar prevenido.

«En derecho inglés, como regla general, una promesa no obliga contractualmente a su autor a menos que revista la forma de deed o que tenga una consideration» ${ }^{206}$. Se podrían invertir los términos de la proposición: a falta de consideration, el deed es necesario para dar fuerza obligatoria a una promesa.

La consideration es ciertamente la exigencia de derecho común, el criterio fundamental que permite distinguir los contratos de acuerdos sin valor contractual $^{207}$. Para que el juez reconozca la existencia de una acción contractual, hace falta que el compromiso invocado haya tenido una consideration, que sea justificada por el sacrificio o el empobrecimiento consentido por su beneficiario. Pero, evidentemente, esta exigencia no se satisface cuando el que se obliga no pretende nada más que la satisfacción de beneficiar a otro. La formalidad del deed toma pues el relevo. Ya que la operación no es económicamente un contrato, solamente a voluntad cierta de aquel que se obliga puede conferirle fuerza obligatoria. Y esta voluntad debe ser confirmada por el cumplimiento de ciertas formalidades. Inicialmente, el deed es un escrito emanado de aquel que se obliga y revestido de su sello (seal). Progresivamente, el sello ha dado paso a menciones equivalentes: inscripción de la palabra seal sobre el acto o las iniciales LS por locus sigili, aposición de una pastilla roja que hace las veces de sello... exigencias todas estas que no tienen otra justificación que llamar la atención de aquel que se obliga sobre el alcance de su obligación. Hoy, el sello ya no se exige a los particulares, pero la exigencia de un escrito permanece. Además, el deed debe ser «expedido». La expedición es un acto que traduce claramente la intención del autor del deed de obligarse: a veces la entrega del documento al beneficiario o a un tercero, pero no necesariamente ${ }^{208}$. Una mención comparable al bon pour que antiguamente se exigía en derecho francés se inscribe sobre el acto, haciendo las veces de expedición del deed: I deliver this as my act and deed. Se trata, una vez más, de verificar la intención de su autor de quedar jurídicamente obligado.

Queda saber si el acto realizado en estas condiciones es o no un contrato. Parece que no, incluso si hablamos comúnmente de contract under

${ }^{206}$ G. H. TREITEL, op. cit., p. 67.

${ }^{207}$ Cf. supra, n. ${ }^{\circ} 3$.

${ }^{208}$ V. G. H. Treitel, op. cit., p. 158; O. Moreteau, Droit anglais des affaires, op. cit., n. ${ }^{\circ} 448$ y ss. 
sea $^{209}$. Por una parte, el acto no deriva su fuerza obligatoria de un acuerdo de voluntades sino del documento, del instrumentum mismo ${ }^{210}$. Por otra parte, está sometido a reglas propias y no al régimen general del «verdadero» contrato ${ }^{211}$. Si el derecho inglés acepta reconocer efectos a los acuerdos sin contrapartida, no por ello estos acuerdos constituirán contratos dado que su función económica es otra.

33. La reciprocidad de las obligaciones no es tratada como tal ni de forma específica por los Principios europeos. Habría sido difícil encontrar una vía intermedia entre la teoría de la causa y la de la consideration ${ }^{212}$. Tan sólo se recoge el sinalagmatismo, pero en la fase del incumplimiento. Algunos artículos regulan los «medios» (recursos) propios a los contratos sinalagmáticos: excepción de incumplimiento (arts. 9.201), resolución (arts. 9.301 a 9.309) y reducción del precio (9.401). Pero la expresión misma de «contrato sinalagmático» sólo aparece en los comentarios. Por lo demás, estas disposiciones no son objeto de un capítulo específico sino que se intercalan entre el «derecho a exigir el cumplimiento» (arts. 9.101 a 9.103) y la indemnización de daños y perjuicios (arts. 9.501 a 9.510). Si no se consideró necesario hacer un apartado especial para los contratos sinalagmáticos, ¿no será porque los Principios, en el fondo muy mercantilistas ${ }^{213}$, han erigido el sinalagmatismo en modelo contractual?

Para finalizar, se mencionaran las soluciones adoptadas por el proyecto Gandolfi. En primer lugar, se suprime toda exigencia de causa o de consideration $^{214}$. El proyecto afirma no obstante que «el contenido del contrato debe ser útil» ${ }^{215}$. Ahí se verá fácilmente una evocación de la dimensión necesariamente económica del contrato, si el artículo 26 del proyecto no precisara que «el contenido del contrato es útil cuando sirve a un interés de ambas partes o al menos de una de ellas». De hecho, la utilidad no es sino la condición sin la cual el contrato no es «serio» ${ }^{216}$. No es, pues, una condición de patrimonialidad, a diferencia de lo que exige por ejemplo el artículo 1174 del Codi-

\footnotetext{
${ }^{209}$ V. O. MoReteau, op. cit., loc. cit.

${ }^{210}$ V. G. H. TREITEL, op. cit., loc. cit.: «The binding force of such a promise does not depend on contract at all».

${ }^{211}$ V. R. David et D. PugsLey, Les contrats en droit anglais, $2^{\text {ème } e ́ d ., ~ L G D J, ~ 1985, ~}$ n. ${ }^{\circ} 201$.

${ }^{212}$ V. para una comparación de las dos nociones R. DAVID, «Cause et Consideration», en Mélanges Maury, t. II, p. 111.

${ }^{213}$ Esta consideración ya se ha apuntado (supra n. $^{\circ} 26$ ), sobre la aplicabilidad de los principios al PACS o más generalmente a las parejas de hecho registradas.

${ }^{214}$ V. Code européen des contrats, Livre I, op. cit., Rapport, p. 100 y ss.

${ }^{215}$ Art. 25.

${ }^{216}$ V. Code européen des contrats, Livre I, op. cit., Rapport, p. 115, expresando la opinión de CARBONNIER, miembro de la Academia.
} 
ce civile italiano ${ }^{217}$. Los autores del proyecto han visto en ello, no obstante, «una condición requerida apta, entre otras cosas, para satisfacer la exigencia del grupo inglés, en el marco de la ausencia de la consideration» ${ }^{218}$.

\section{CONCLUSIÓN}

34. Retornemos a la doble afirmación que ha estructurado este estudio: «el contrato no existe sin acuerdo de voluntades; tan sólo interesa al Derecho en la medida en que resulta generador de obligaciones». Las palabras que anteceden han mostrado suficientemente que ninguna de estas afirmaciones era exacta. Desde luego, la mayor parte de las situaciones contractuales tienen como punto de partida un intercambio de consentimientos; pero el derecho del contrato es a menudo impuesto a personas que no han consentido en ello o más allá de los límites que los contratantes habían previsto. Ciertamente, el modelo contractual es generador de obligaciones; pero no solamente algunos contratos imponen obligaciones, además los distintos sistemas jurídicos no se ponen de acuerdo sobre las obligaciones que dan lugar a una situación su naturaleza contractual. De ello se deriva que ni el acuerdo de las partes ni la existencia de obligaciones a su cargo permiten definir el contrato, y menos aún delimitarlo.

Otras definiciones son posibles. La más convincente es aquella que se funda sobre la función socioeconómica del contrato. La mayor parte de las extensiones del contrato en derecho francés tienen como causa la voluntad de hacerlo desempeñar un papel que no es el suyo: el papel de un principio de reparación alternativo a la responsabilidad extracontractual, un principio más atractivo, disponible siempre que el juez pueda establecer un vínculo entre las partes del litigio, por lejano que parezca. Que se piense, por ejemplo, en el intuitus rei en los grupos de contratos o en la proyección familiar del contrato de transporte que protege tanto a los padres como a la víctima misma. Es probable que volviendo a la función esencial del contrato -si no la producción, al menos la previsión- se eviten un cierto número de incertidumbres, de subjetivismo y, por tanto, de divergencias nacionales de interpretación.

Se ha constatado igualmente que el criterio de la fuente de la relación de obligación (las partes o la ley) permitía una separación bastante clara ente lo que es contractual y lo que no. Este criterio no es forzosamente incompatible con el precedente: respetar la función de previsión del contrato es rechazar integrar en él todas esas obligaciones sobre las que la previsión de las partes no ha reparado.

217 «La prestación objeto de la obligación debe ser susceptible de una evaluación económica y corresponder a un interés, incluso no patrimonial, del acreedor».

${ }^{218}$ Code européen des contrats, Livre I, op. cit., Rapport, p. 115. 
Una u otra, bien habrá que esforzarse en dar una definición uniforme del contrato antes de unificar las reglas. Porque, sea cual sea la calidad de éstas, no tendrán más que una aplicación limitada si no se llega a un acuerdo previo sobre su dominio material de aplicación. 